\title{
pLoc_Deep-mHum: Predict Subcellular Localization of Human Proteins by Deep Learning
}

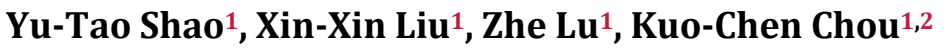 \\ ${ }^{1}$ Computer Science, Jingdezhen Ceramic Institute, Jingdezhen, China; ${ }^{2}$ Gordon Life Science Institute, Boston, MA \\ 02478, USA
}

Correspondence to: Yu-Tao Shao, 532606318@qq.com; Xin-Xin Liu, 1332250394@qq.com; Zhe Lu, 454170054@qq.com; Kuo-Chen Chou, kcchou@gordonlifescience.org, kcchou38@gmail.com

Keywords: Coronavirus; Multi-Label System; Human Proteins; Deep Learning; Five-Steps Rule; PseAAC

Received: July 15, $2020 \quad$ Accepted: July 24, $2020 \quad$ Published: July 27, 2020

Copyright $\odot 2020$ by author(s) and Scientific Research Publishing Inc.

This work is licensed under the Creative Commons Attribution International License (CC BY 4.0).

http://creativecommons.org/licenses/by/4.0/

\section{(c) (i) Open Access}

\section{ABSTRACT}

Recently, the life of human beings around the entire world has been endangering by the spreading of pneumonia-causing virus, such as Coronavirus, COVID-19, and H1N1. To develop effective drugs against Coronavirus, knowledge of protein subcellular localization is indispensable. In 2019, a predictor called "pLoc_bal-mHum" was developed for identifying the subcellular localization of human proteins. Its predicted results are significantly better than its counterparts, particularly for those proteins that may simultaneously occur or move between two or more subcellular location sites. However, more efforts are definitely needed to further improve its power since pLoc_bal-mHum was still not trained by a "deep learning", a very powerful technique developed recently. The present study was devoted to incorporate the "deep-learning" technique and develop a new predictor called "pLoc_Deep-mHum". The global absolute true rate achieved by the new predictor is over $81 \%$ and its local accuracy is over $90 \%$. Both are overwhelmingly superior to its counterparts. Moreover, a user-friendly web-server for the new predictor has been well established at http://www.jci-bioinfo.cn/pLoc_Deep-mHum/, which will become a very useful tool for fighting pandemic coronavirus and save the mankind of this planet.

\section{INTRODUCTION}

Knowledge of the subcellular localization of proteins is crucially important for fulfilling the following two important goals: 1) revealing the intricate pathways that regulate biological processes at the cellular level [1,2]. 2) selecting the right targets [3] for developing new drugs.

With the avalanche of protein sequences in the post-genomic age, we are challenged to develop computational tools for effectively identifying their subcellular localization purely based on the sequence in- 
formation.

The development of predicting human subcellular localization can be briefly summarized as follows. The early human protein predictor HSLPred [4] can only predict four subcellular localizations. In 2006, Chou et al. developed Hum-PLoc [5], which can cover up to 12 subcellular localizations, but Hum-PLoc can only predict a single position. In 2011, by extracting the GO (Gene Ontology) information of the proteins [6], the same predictor can be used to deal with multiple locations proteins, achieving $76 \%$ accuracy. It is through these kinds of procedures and follow-up procedures, that the capacity in dealing with multi-site systems and raising the accuracy is further improved. Particularly for the predictor called pLoc_bal-mHum [6].

Although the pLoc_bal-mHum predictor [7] has the aforementioned merits, it has not been trained at a deeper level yet [8-11].

The present study was initiated in an attempt to address this problem. As done in pLoc_bal-mHum [12] as well as many other recent publications in developing new prediction methods (see, e.g., [9-11, 13-50]), the guidelines of the 5-step rule [51] are followed. They are about the detailed procedures for 1) benchmark dataset, 2) sample formulation, 3) operation engine or algorithm, 4) cross-validation, and 5) web-server. But here our attentions are focused on the procedures that significantly differ from those in developing the predictor pLoc_bal-mHum [12].

\section{MATERIALS AND METHODS}

\subsection{Benchmark Dataset}

The benchmark dataset used in this study is exactly the same as that in pLoc_bal-mHum [12]. It can be formulated as

$$
\mathbb{S}=\mathbb{S}_{1} \cup \mathbb{S}_{2} \cup \cdots \cup \mathbb{S}_{u} \cup \cdots \cup \mathbb{S}_{13} \cup \mathbb{S}_{14}
$$

where $\mathbb{S}_{1}$ only contains the protein samples from the "Centrosome" location (cf. Table 1 ), $\mathbb{S}_{2}$ only contains those from the "Cytoplasm" location, and so forth; $U$ denotes the symbol for "union" in the set theory [52]. The detailed sequences of these proteins and their accession numbers (or ID codes) are given in Supporting Information S1 that is also available at http://www.jci-bioinfo.cn/pLoc_bal-mHum/Supp1.pdf where none of proteins included has $\geq 25 \%$ sequence identity to any other in the same subset.

\subsection{Proteins Sample Formulation}

Now let us consider the $2^{\text {nd }}$ step of the 5-step rule [51]; i.e., how to formulate the biological sequence samples with an effective mathematical expression that can truly reflect their essential correlation with the target concerned. Given a protein sequence $\mathbf{P}$, its most straightforward expression is

Table 1. Comparison with the state-of-the-art method in predicting human protein subcellular localization $^{\mathrm{a}}$.

\begin{tabular}{cccccc}
\hline \multicolumn{1}{c}{ Predictor } & $\begin{array}{c}\text { Aiming } \\
(\uparrow)^{\mathrm{a}}\end{array}$ & $\begin{array}{c}\text { Coverage } \\
(\uparrow)^{\mathrm{a}}\end{array}$ & $\begin{array}{c}\text { Accuracy } \\
(\uparrow)^{\mathrm{a}}\end{array}$ & $\begin{array}{c}\text { Absolute true } \\
(\uparrow)^{\mathrm{a}}\end{array}$ & $\begin{array}{c}\text { Absolute false } \\
(\downarrow)^{\mathrm{a}}\end{array}$ \\
\hline pLoc_bal-mHum $^{\mathrm{b}}$ & $92.06 \%$ & $94.54 \%$ & $92.29 \%$ & $89.28 \%$ & $0.48 \%$ \\
pLoc_Deep-Hum $^{\mathrm{c}}$ & $98.00 \%$ & $97.66 \%$ & $97.36 \%$ & $96.47 \%$ & $0.00 \%$ \\
\hline
\end{tabular}

${ }^{a}$ See Eq. 4 for the definition of the metrics. ${ }^{b}$ See [12], where the reported metrics rates were obtained by the jackknife test on the benchmark dataset of Supporting Information S1 that contains experiment-confirmed proteins only. 'The proposed predictor; to assure that the test was performed on exactly the same experimental data as reported in [12] for pLoc_bal-mHum. 


$$
\mathbf{P}=\mathrm{R}_{1} \mathrm{R}_{2} \mathrm{R}_{3} \mathrm{R}_{4} \mathrm{R}_{5} \mathrm{R}_{6} \mathrm{R}_{7} \cdots \mathrm{R}_{L}
$$

where $L$ denotes the protein's length or the number of its constituent amino acid residues, $\mathrm{R}_{1}$ is the $1^{\text {st }}$ residue, $R_{2}$ the $2^{\text {nd }}$ residue, $R_{3}$ the $3^{\text {rd }}$ residue, and so forth. Since all the existing machine-learning algorithms\} can only handle vectors as elaborated in [3], one has to convert a protein sample from its sequential expression (Equation (2)) to a vector. But a vector defined in a discrete model might completely miss all the sequence-order or pattern information. To deal with this problem, the Pseudo Amino Acid Composition [53] or PseAAC [54]. Ever since then, the concept of "Pseudo Amino Acid Composition" or "PseAAC" has been widely used in nearly all the areas of computational proteomics with the aim to grasp various different sequence patterns that are essential to the targets investigated (see, e.g., [11, 55-207]).

Because it has been widely and increasingly used, recently three powerful open access soft-wares, called "PseAAC-Builder" [87], "propy" [144], and "PseAAC-General" [114], were established: the former two are for generating various modes of special PseAAC [208]; while the 3rd one for those of general PseAAC [51], including not only all the special modes of feature vectors for proteins but also the higher level feature vectors such as "Functional Domain" mode, "Gene Ontology" mode, and "Sequential Evolution" or "PSSM" mode. Encouraged by the successes of using PseAAC to deal with protein/peptide sequences, its idea and approach were extended to PseKNC (Pseudo K-tuple Nucleotide Composition) to generate various feature vectors for DNA/RNA sequences [209] that have proved very successful as well [210-221]. According to the concept of general PseAAC [51], any protein sequence can be formulated as a PseAAC vector given by

$$
\begin{aligned}
& \mathbf{P}=\left[\begin{array}{llllll}
\Psi_{1} & \Psi_{2} & \cdots & \Psi_{u} & \cdots & \Psi_{\Omega}
\end{array}\right]^{\mathbf{T}} \\
& \mathbf{P}=\left[\begin{array}{llllll}
\Psi_{1} & \Psi_{2} & \cdots & \Psi_{u} & \cdots & \Psi_{\Omega}
\end{array}\right]^{\mathbf{T}}
\end{aligned}
$$

where $\mathrm{T}$ is a transpose operator, while the integer $\Omega$ is a parameter and its value as well as the components $\Psi_{u} \quad(u=1,2, \cdots, \Omega)$ will depend on how to extract the desired information from the amino acid sequence of $\mathbf{P}$, as elaborated in [12]. Thus, by following exactly the same procedures as described in the Section 2.2 of [12], each of the protein samples in the benchmark dataset can be uniquely defined as a 14-D numerical vector as given in columns 16 - 29 of Supporting Information S2, which can also be directly downloaded at http://www.jci-bioinfo.cn/pLoc_bal-mHum/Supp2.pdf.

\subsection{Architecture for the Novel CNN-BiLSTM Network}

In this study, a novel deep CNN-BiLSTM neural network (Figure 1) model included one convolution layer and one BiLSTM block is proposed to predict subcellular localization of multi-label human proteins. The strong point of this model is that it allows extracting the maximum amount of information from human protein features using CNN convolution layers. This output becomes the BiLSTM input, which allows keeping the dependency relationship between the features in both directions.

CNN is known for its ability to extract as many features as possible from the data. In our model, 14 human protein features are used as convolutional neural network input. Then, fourteen filters of sizes 2 with a stride of 1 are applied. This gives a $14^{\star} 14$ feature map. After each filter, a layer of MaxPooling1D is applied to update and reduce the size of the data and this gives a $7^{\star} 14$ feature map.

Then, the $7 * 14$ feature map is concatenated to build the BiLSTM input, which applies a BiLSTM layer to filter the information, using its three gates. The output of this step is the input of the fully connected layer which consists of 3 hidden layer. It links each piece of input information with a piece of output information. Finally, we apply the sigmoid function as an activation function in order to transform the vector into probability to define the class of each output. The label of human protein was decided by the Probability value $\theta$. If the output is greater than 0.5 , the outcome was true; otherwise, false.

The new predictor developed via the above procedures is called "pLoc_Deep-mHum", where "pLoc_Deep" stands for "predict subcellular localization by deep learning", and "mHum" for "multi-label human proteins". 


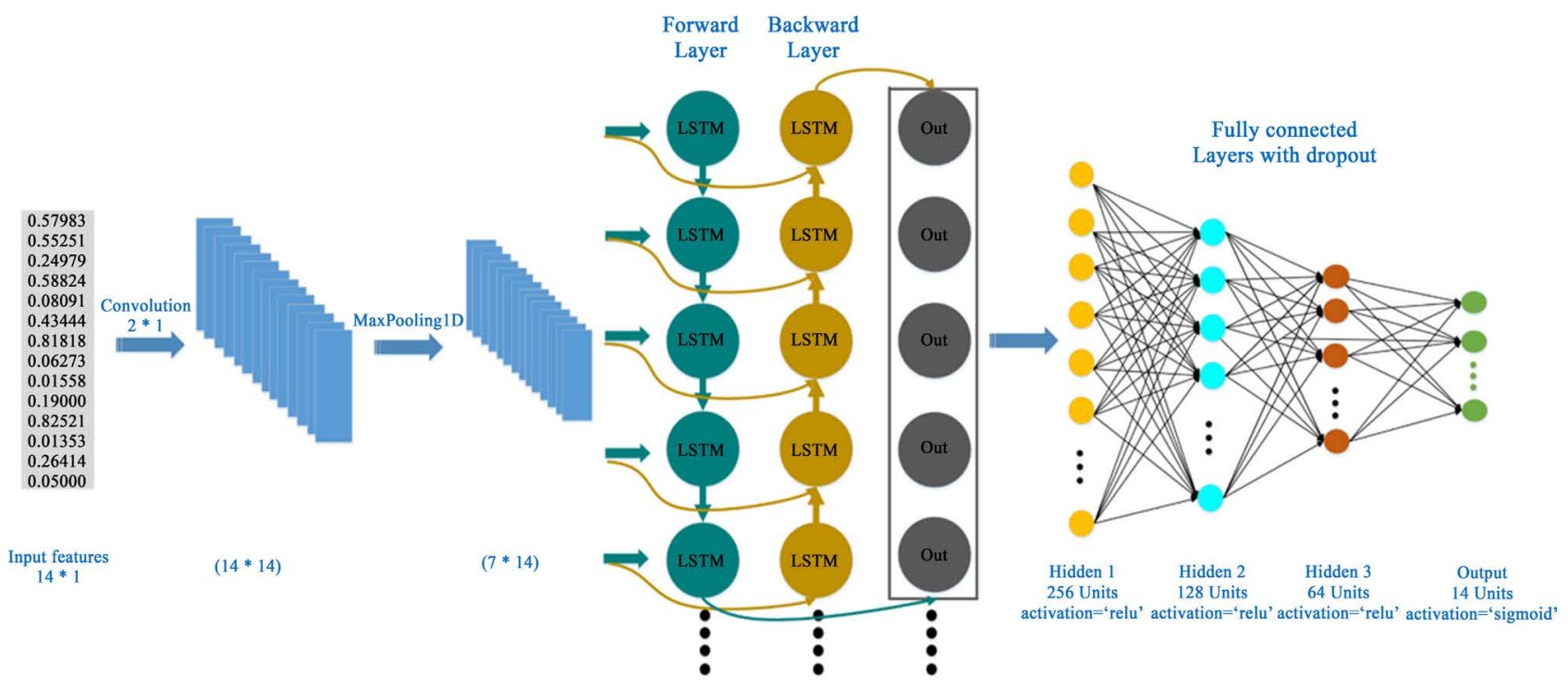

Figure 1. An illustration to show a CNN and LSTM neural network models to predict the subcellular localization of human proteins.

The new predictor developed via the above procedures is called "pLoc_Deep-mHum", where "pLoc_Deep" stands for "predict subcellular localization by deep learning", and "mHum" for "multi-label human proteins".

\section{RESULTS AND DISCUSSION}

According to the 5-step rules [51], one of the important procedures in developing a new predictor is how to properly evaluate its anticipated accuracy. To deal with that, two issues need to be considered. 1) What metrics should be used to quantitatively reflect the predictor's quality? 2) What test method should be applied to score the metrics?

\subsection{A Set of Five Metrics for Multi-Label Systems}

Different from the metrics used to measure the prediction quality of single-label systems, the metrics for the multi-label systems are much more complicated [222]. For the latter, two kinds of metrics are needed: one is the "global metrics" and the other is the "local metrics".

\subsection{Comparison with the State-of-the-Art Predictor}

Listed in Table 1 are the rates achieved by the current pLoc_Deep-mHum predictor via the cross validations on the same experiment-confirmed dataset as used in [22] according to the scores of "global metrics". For facilitating comparison, listed there are also the corresponding results obtained by the pLoc_bal-mHum [12], the existing most powerful predictor for identifying the subcellular localization of human proteins with both single and multiple location sites. As shown in Table 1, the newly proposed predictor pLoc_Deep-mHum is remarkably superior to the existing state-of-the-art predictor pLoc_bal-mHum in all the five metrics. Particularly, it can be seen from the table that the absolute true rate achieved by the new predictor is over $81 \%$, which is far beyond the reach of any other existing methods. This is because it is extremely difficult to enhance the absolute true rate of a prediction method for a multi-label system as clearly elucidated in [12]. Actually, to avoid embarrassment, many investigators even chose not to mention the metrics of absolute true rate in dealing with multi-label systems (see, e.g., [85, 141, 147]).

Moreover, to in-depth examine the prediction quality of the new predictor for the proteins in each of the subcellular locations concerned (cf. Table 2), we used a set of four "local metrics" to score its accuracy, 
Table 2. Performance of pLoc_Deep-mHum for each of the 14 subcellular locations.

\begin{tabular}{cccccc}
\hline$i$ & Location $^{\mathrm{a}}$ & $\operatorname{Sn}(i)^{\mathrm{b}}$ & $\operatorname{Sp}(i)^{\mathrm{b}}$ & $\operatorname{Acc}(i)^{\mathrm{b}}$ & $\operatorname{MCC}(i)^{\mathrm{b}}$ \\
\hline 1 & Centrosome & 0.9836 & 0.9988 & 0.9976 & 0.9831 \\
2 & Cytoplasm & 0.9338 & 0.9890 & 0.9851 & 0.8898 \\
3 & Cytoskeleton & 0.9949 & 0.9992 & 0.9989 & 0.9920 \\
4 & Endoplasmic reticulum & 0.9801 & 0.9986 & 0.9973 & 0.9805 \\
5 & Endosome & 0.9960 & 0.9994 & 0.9991 & 0.9935 \\
6 & Extracellular & 0.9850 & 0.9978 & 0.9968 & 0.9771 \\
7 & Golgi apparatus & 0.9753 & 0.9982 & 0.9965 & 0.9745 \\
8 & Lysosome & 0.9991 & 0.9994 & 0.9994 & 0.9957 \\
9 & Microsome & 0.9971 & 0.9999 & 0.9997 & 0.9980 \\
10 & Mitochondrion & 0.9845 & 0.9986 & 0.9976 & 0.9827 \\
11 & Nucleus & 0.9409 & 0.9917 & 0.9880 & 0.9129 \\
12 & Peroxisome & 0.9981 & 1.0000 & 0.9999 & 0.9990 \\
13 & Plasma membrane & 0.9792 & 0.9981 & 0.9967 & 0.9760 \\
14 & Synapse & 1.0000 & 0.9999 & 0.9999 & 0.9995 \\
\hline
\end{tabular}

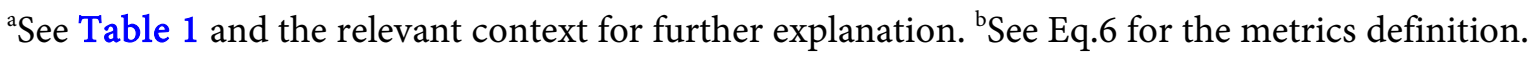

which were derived in [223] based on the Chou's symbols introduced for studying protein signal peptides [224] and that have ever since been widely concurred or justified (see, e.g., [209-217, 223, 225-274]).

Listed in Table 2 are the rates achieved by pLoc_Deep-mHum for the human proteins in each of 22 subcellular locations. As we can see from the table, nearly all the success rates achieved by the new predictor for the human proteins in each of the 22 subcellular locations are within the range of $90 \%-100 \%$, which is once again far beyond the reach of any of its counterparts.

Meanwhile, as a byproduct, the present paper has also stimulated some very interesting or challenging papers (see, e.g., [275-280]).

\subsection{Comparison with Several Classic Machine Learning Methods}

In this paper, the CNN-BiLSTM neural network model is constructed through the Python language and Keras, and the model is trained through binary_crossentropy and Adam optimizers $(\mathrm{lr}=0.001$, beta_1 $=0.9$, beta $22=0.999$, epsilon $=10^{-8}$ ).

In order to improve the performance of the CNN-BiLSTM neural network model, based on the above parameter settings, the hyperparameters of the constructed CNN-BiLSTM model are adjusted. Through experimental analysis, we find that four parameters have a greater impact on the performance of the deep learning model: the height of the CNN filter, the number of filters in the convolutional layer, the output dimension of BiLSTM, and Dropout rate. Finally, the four optimal parameters are set to $(2,14,14,0.1)$.

We compared the performance of the pLoc_Deep-mHum model with seven state-of-the-art methods in Table 3, including Rake1D [281], LabelPowerset [282], ML-SVM [283], MLARAM\{Benites, 2015 \#8224\}, RandomForestClassifier [284], MLKNN [285], BRkNNaClassifier\{Spyromitros, 2008 \#8227\}. It 
Table 3. Comparison with several classic machine learning methods in predicting human protein subcellular localization ${ }^{\mathrm{a}}$.

\begin{tabular}{cccccc}
\hline Predictor & Aiming $(\uparrow)^{\mathrm{a}}$ & $\begin{array}{c}\text { Coverage } \\
(\uparrow)^{\mathrm{a}}\end{array}$ & $\begin{array}{c}\text { Accuracy } \\
(\uparrow)^{\mathrm{a}}\end{array}$ & $\begin{array}{c}\text { Absolute true } \\
(\uparrow)^{\mathrm{a}}\end{array}$ & $\begin{array}{c}\text { Absolute } \\
\text { false }(\downarrow)^{\mathrm{a}}\end{array}$ \\
\hline Rake1D & $85.47 \%$ & $88.61 \%$ & $84.52 \%$ & $79.96 \%$ & $0.00 \%$ \\
LabelPowerset & $85.44 \%$ & $88.38 \%$ & $84.55 \%$ & $80.40 \%$ & $0.00 \%$ \\
ML-SVM & $85.19 \%$ & $85.67 \%$ & $84.61 \%$ & $82.95 \%$ & $0.00 \%$ \\
MLARAM & $93.42 \%$ & $97.13 \%$ & $92.59 \%$ & $87.94 \%$ & $0.00 \%$ \\
RandomForestClassifier & $90.14 \%$ & $89.63 \%$ & $89.58 \%$ & $88.98 \%$ & $0.00 \%$ \\
MLKNN & $93.93 \%$ & $93.88 \%$ & $92.91 \%$ & $90.98 \%$ & $0.00 \%$ \\
BRkNNaClassifier & $95.26 \%$ & $94.28 \%$ & $94.08 \%$ & $92.79 \%$ & $0.00 \%$ \\
Full-Dense-connected & $97.52 \%$ & $97.32 \%$ & $96.67 \%$ & $95.14 \%$ & $0.00 \%$ \\
pLoc_Deep-Hum ${ }^{\mathrm{c}}$ & $98.00 \%$ & $97.66 \%$ & $97.36 \%$ & $96.47 \%$ & $0.00 \%$ \\
\hline
\end{tabular}

can be found that the performance of the pLoc_Deep-mHum model is significantly better than its cohorts in the multi-label metrics scores.

As pointed out in [286], user-friendly and publicly accessible web-servers represent the future direction for developing practically more useful predictors. Actually, user-friendly web-servers as given in a series of recent publications (see, e.g., Song, 2018 \#3338; Wang, 2018 \#3353\}) will significantly enhance the impacts of theoretical work because they can attract the broad experimental scientists [287]. In view of this, the web-server of the current pLoc_Deep-mHum predictor has also been established at http://www.jci-bioinfo.cn/pLoc_Deep-mHum/, by which the majority of experimental scientists can easily get the data they need.

\section{CONCLUSION}

It is anticipated that the pLoc_Deep-Hum predictor holds very high potential to become a useful high throughput tool in identifying the subcellular localization of human proteins, particularly for finding multi-target drugs that is currently a very hot trend in drug development. Particularly, it will become a very useful tool to find novel drugs against the current pandemic of Coronavirus endangering mankind's life.

\section{ACKNOWLEDGMENTS}

This work was supported by the grants from the National Natural Science Foundation of China (No. $31560316,61261027,61262038,61202313$ and 31260273), the Province National Natural Science Foundation of Jiangxi (No. 20132BAB201053), the Jiangxi Provincial Foreign Scientific and Technological Cooperation Project (No.20120BDH80023), the Department of Education of Jiangxi Province (GJJ160866).

\section{CONFLICTS OF INTEREST}

The authors declare no conflicts of interest regarding the publication of this paper.

\section{REFERENCES}

1. Ehrlich, J.S., Hansen, M.D. and Nelson, W.J. (2002) Spatio-Temporal Regulation of Rac1 Localization and La- 
mellipodia Dynamics during Epithelial Cell-Cell Adhesion. Developmental Cell, 3, 259-270.

https://doi.org/10.1016/S1534-5807(02)00216-2

2. Glory, E. and Murphy, R.F. (2007) Automated Subcellular Location Determination and High-Throughput Microscopy. Developmental Cell, 12, 7-16. https://doi.org/10.1016/j.devcel.2006.12.007

3. Chou, K.C. (2015) Impacts of Bioinformatics to Medicinal Chemistry. Medicinal Chemistry, 11, 218-234. https://doi.org/10.2174/1573406411666141229162834

4. Garg, A., Bhasin, M. and Raghava, G.P. (2005) Support Vector Machine-Based Method for Subcellular Localization of Human Proteins Using Amino Acid Compositions, Their Order, and Similarity Search. The Journal of Biological Chemistry, 280, 14427-14432. https://doi.org/10.1074/jbc.M411789200

5. Chou, K.C. and Shen, H.B. (2006) Addendum to "Hum-PLoc: A Novel Ensemble Classifier for Predicting Human Protein Subcellular Localization”. Biochemical and Biophysical Research Communications, 348, 1479. https://doi.org/10.1016/j.bbrc.2006.08.030

6. Chou, K.C. (2019) Showcase to Illustrate How the Web-Server iNitro-Tyr Is Working. Global Journal of Computer Science and Information Technology, 2, 1-16.

7. Chou, K.C. (2019) An Insightful Recollection for Predicting Protein Subcellular Locations in Multi-Label Systems. Genomics.

https://www.sciencedirect.com/science/article/pii/S0888754319304604?via\%3Dihub https://doi.org/10.1016/j.ygeno.2019.08.008

8. Maxwell, A., Li, R., Yang, B., Weng, H., Ou, A., Hong, H., Zhou, Z., Gong, P. and Zhang, C. (2017) Deep Learning Architectures for Multi-Label Classification of Intelligent Health Risk Prediction. BMC Bioinformatics, 18, 523. https://doi.org/10.1186/s12859-017-1898-z

9. Barukab, O., Khan, Y.D., Khan, S.A. and Chou, K.C. (2019) iSulfoTyr-PseAAC: Identify Tyrosine Sulfation Sites by Incorporating Statistical Moments via Chou's 5-Steps Rule and Pseudo Components Current Genomics, 20, 306-320. https://doi.org/10.2174/1389202920666190819091609

10. Khan, Y.D., Amin, N., Hussain, W., Rasool, N., Khan, S.A. and Chou, K.C. (2020) iProtease-PseAAC(2L): A Two-Layer Predictor for Identifying Proteases and Their Types Using Chou's 5-Step-Rule and General PseAAC. Analytical Biochemistry, 588, Article ID: 113477. https://doi.org/10.1016/j.ab.2019.113477

11. Nazari, I., Tahir, M., Tayari, H. and Chong, K.T. (2019) iN6-Methyl (5-Step): Identifying RNA N6-Methyladenosine Sites Using Deep Learning Mode via Chou's 5-Step Rules and Chou's General PseKNC. Chemometrics and Intelligent Laboratory Systems (CHEMOLAB). https://doi.org/10.1016/j.chemolab.2019.103811

12. Chou, K.C., Cheng, X. and Xiao, X. (2019) pLoc_bal-mHum: Predict Subcellular Localization of Human Proteins by PseAAC and Quasi-Balancing Training Dataset. Genomics, 111, 1274-1282.

https://doi.org/10.1016/j.ygeno.2018.08.007

13. Butt, A.H. and Khan, Y.D. (2018) Prediction of S-Sulfenylation Sites Using Statistical Moments Based Features via Chou's 5-Step Rule. International Journal of Peptide Research and Therapeutics (IJPRT). https://doi.org/10.1007/s10989-019-09931-2

14. Awais, M., Hussain, W., Khan, Y.D., Rasool, N., Khan, S.A. and Chou, K.C. (2019) iPhosH-PseAAC: Identify Phosphohistidine Sites in Proteins by Blending Statistical Moments and Position Relative Features According to the Chou's 5-Step Rule and General Pseudo Amino Acid Composition. IEEE/ ACM Transactions on Computational Biology and Bioinformatics. https://doi.org/10.1109/TCBB.2019.2919025

15. Butt, A.H. and Khan, Y.D. (2019) Prediction of S-Sulfenylation Sites Using Statistical Moments Based Features via Chou's 5-Step Rule. International Journal of Peptide Research and Therapeutics (IJPRT).

https://doi.org/10.1007/s10989-019-09931-2 
16. Chen, Y. and Fan, X. (2019) Use Chou's 5-Steps Rule to Reveal Active Compound and Mechanism of Shuangsheng Pingfei San on Idiopathic Pulmonary Fibrosis. Current Molecular Medicine, 20, No. 3. https://doi.org/10.2174/1566524019666191011160543

17. Du, X., Diao, Y., Liu, H. and Li, S. (2019) MsDBP: Exploring DNA-Binding Proteins by Integrating Multi-Scale Sequence Information via Chou's 5-Steps Rule. Journal of Proteome Research, 18, 3119-3132. https://doi.org/10.1021/acs.jproteome.9b00226

18. Dutta, A., Dalmia, A., Singh, K.K. and Anand, A. (2019) Using the Chou's 5-Steps Rule to Predict Splice Junctions with Interpretable Bidirectional Long Short-Term Memory Networks. Computers in Biology and Medicine, 116, Article ID: 103558. https://doi.org/10.1016/j.compbiomed.2019.103558

19. Ehsan, A., Mahmood, M.K., Khan, Y.D., Barukab, O.M., Khan, S.A. and Chou, K.C. (2019) iHyd-PseAAC (EPSV): Identify Hydroxylation Sites in Proteins by Extracting Enhanced Position and Sequence Variant Feature via Chou's 5-Step Rule and General Pseudo Amino Acid Composition. Current Genomics, 20, 124-133. https://doi.org/10.2174/1389202920666190325162307

20. Hussain, W., Khan, S.D., Rasool, N., Khan, S.A. and Chou, K.C. (2019) SPalmitoylC-PseAAC: A Sequence-Based Model Developed via Chou's 5-Steps Rule and General PseAAC for Identifying S-Palmitoylation Sites in Proteins. Analytical Biochemistry, 568, 14-23. https://doi.org/10.1016/j.ab.2018.12.019

21. Hussain, W., Khan, Y.D., Rasool, N., Khan, S.A. and Chou, K.C. (2019) SPrenylC-PseAAC: A Sequence-Based Model Developed via Chou's 5-Steps Rule and General PseAAC for Identifying S-Prenylation Sites in Proteins. Journal of Theoretical Biology, 468, 1-11. https://doi.org/10.1016/j.jtbi.2019.02.007

22. Jun, Z. and Wang, S.Y. (2019) Identify Lysine Neddylation Sites Using Bi-Profile Bayes Feature Extraction via the Chou's 5-Steps Rule and General Pseudo Components. Current Genomics, 20, 592-601. https://doi.org/10.2174/1389202921666191223154629

23. Khan, S., Khan, M., Iqbal, N., Hussain, T., Khan, S.A. and Chou, K.C. (2019) A Two-Level Computation Model Based on Deep Learning Algorithm for Identification of piRNA and Their Functions via Chou's 5-Steps Rule. Human Genetics. https://doi.org/10.1007/s10989-019-09887-3

24. Khan, Z.U., Ali, F., Khan, I.A., Hussain, Y. and Pi, D. (2019) iRSpot-SPI: Deep Learning-Based Recombination Spots Prediction by Incorporating Secondary Sequence Information Coupled with Physio-Chemical Properties via Chou's 5-Step Rule and Pseudo Components. Chemometrics and Intelligent Laboratory Systems (CHEMOLAB), 189, 169-180. https://doi.org/10.1016/j.chemolab.2019.05.003

25. Lan, J., Liu, J., Liao, C., Merkler, D.J., Han, Q. and Li, J. (2019) A Study for Therapeutic Treatment against Parkinson's Disease via Chou's 5-Steps Rule. Current Topics in Medicinal Chemistry. http://www.eurekaselect.com/175887/article https://doi.org/10.2174/1568026619666191019111528

26. Le, N.Q.K. (2019) iN6-Methylat (5-Step): Identifying DNA N(6)-Methyladenine Sites in Rice Genome Using Continuous Bag of Nucleobases via Chou's 5-Step Rule. Molecular Genetics and Genomics. MGG, 294, 1173-1182. https://doi.org/10.1007/s00438-019-01570-y

27. Le, N.Q.K., Yapp, E.K.Y., Ho, Q.T., Nagasundaram, N., Ou, Y.Y. and Yeh, H.Y. (2019) iEnhancer-5Step: Identifying Enhancers Using Hidden Information of DNA Sequences via Chou's 5-Step Rule and Word Embedding. Analytical Biochemistry, 571, 53-61. https://doi.org/10.1016/j.ab.2019.02.017

28. Le, N.Q.K., Yapp, E.K.Y., Ou, Y.Y. and Yeh, H.Y. (2019) iMotor-CNN: Identifying Molecular Functions of Cytoskeleton Motor Proteins Using 2D Convolutional Neural Network via Chou's 5-Step Rule. Analytical Biochemistry, 575, 17-26. https://doi.org/10.1016/j.ab.2019.03.017

29. Liang, R., Xie, J., Zhang, C., Zhang, M., Huang, H., Huo, H., Cao, X. and Niu, B. (2019) Identifying Cancer Targets Based on Machine Learning Methods via Chou's 5-Steps Rule and General Pseudo Components. Current 
Topics in Medical Chemistry. https://doi.org/10.2174/1568026619666191016155543

30. Liang, Y. and Zhang, S. (2019) Identifying DNase I Hypersensitive Sites Using Multi-Features Fusion and F-Score Features Selection via Chou’s 5-Steps Rule. Biophysical Chemistry, 253, Article ID: 106227. https://doi.org/10.1016/j.bpc.2019.106227

31. Liu, Z., Dong, W., Jiang, W. and He, Z. (2019) csDMA: An Improved Bioinformatics Tool for Identifying DNA 6 mA Modifications via Chou's 5-Step Rule. Scientific Reports, 9, Article No. 13109. https://doi.org/10.1038/s41598-019-49430-4

32. Malebary, S.J., Rehman, M.S.U. and Khan, Y.D. (2019) iCrotoK-PseAAC: Identify Lysine Crotonylation Sites by Blending Position Relative Statistical Features According to the Chou's 5-Step Rule. PLoS ONE, 14, e0223993. https://doi.org/10.1371/journal.pone.0223993

33. Ning, Q., Ma, Z. and Zhao, X. (2019) dForml(KNN)-PseAAC: Detecting Formylation Sites from Protein Sequences Using K-Nearest Neighbor Algorithm via Chou's 5-Step Rule and Pseudo Components. Journal of Theoretical Biology, 470, 43-49. https://doi.org/10.1016/j.jtbi.2019.03.011

34. Tahir, M., Tayara, H. and Chong, K.T. (2019) iDNA6mA 5-Step Rule, Identification of DNA N6-Methyladenine Sites in the Rice Genome by Intelligent Computational Model via Chou's 5-Step Rule. CHEMOLAB, 189, 96-101. https://doi.org/10.1016/j.chemolab.2019.04.007

35. Wiktorowicz, A., Wit, A., Dziewierz, A., Rzeszutko, L., Dudek, D. and Kleczynski, P. (2019) Calcium Pattern Assessment in Patients with Severe Aortic Stenosis via the Chou's 5-Steps Rule. Current Pharmaceutical Design. https://doi.org/10.2174/1381612825666190930101258

36. Yang, L., Lv, Y., Wang, S., Zhang, Q., Pan, Y., Su, D., Lu, Q. and Zuo, Y. (2019) Identifying FL11 Subtype by Characterizing Tumor Immune Microenvironment in Prostate Adenocarcinoma via Chou's 5-Steps Rule. Genomics. https://doi.org/10.1016/j.ygeno.2019.08.021

37. Akbar, S., Rahman, A.U., Hayat, M., et al. (2020) cACP: Classifying Anticancer Peptides Using Discriminative Intelligent Model via Chou's 5-Step Rules and General Pseudo Components. Chemometrics and Intelligent Laboratory (CHEMOLAB), 196, Article ID: 103912. https://doi.org/10.1016/j.chemolab.2019.103912

38. Akmal, M.A., Hussain, W., Rasool, N., Khan, Y.D., Khan, S.A. and Chou, K.C. (2020) Using Chou's 5-Steps Rule to Predict O-Linked Serine Glycosylation Sites by Blending Position Relative Features and Statistical Moment. IEEE/ ACM Transactions on Computational Biology and Bioinformatics. https://doi.org/10.1109/TCBB.2020.2968441

39. Charoenkwan, P., Schaduangrat, N., Nantasenamat, C., Piacham, T. and Shoombuatong, W. (2020) iQSP: A Sequence-Based Tool for the Prediction and Analysis of Quorum Sensing Peptides via Chou's 5-Steps Rule and Informative Physicochemical Properties. International Journal of Molecular Sciences, 21, 75. https://doi.org/10.3390/ijms21010075

40. Charoenkwan, P., Schaduangrat, N., Nantasenamat, C., Piacham, T. and Shoombuatong, W. (2020) Correction: Shoombuatong, W., et al. iQSP: A Sequence-Based Tool for the Prediction and Analysis of Quorum Sensing Peptides via Chou's 5-Steps Rule and Informative Physicochemical Properties. International Journal of Molecular Sciences, 21, 75. https://doi.org/10.3390/ijms21072629

41. Chen, Y. and Fan, X. (2020) Use of Chou's 5-Steps Rule to Reveal Active Compound and Mechanism of Shuangshen Pingfei San on Idiopathic Pulmonary Fibrosis. Current Molecular Medicine, 20, 220-230. https://doi.org/10.2174/1566524019666191011160543

42. Dobosz, R., Mucko, J. and Gawinecki, R. (2020) Using Chou's 5-Step Rule to Evaluate the Stability of Tautomers: Susceptibility of 2-[(Phenylimino)-methyl]-cyclohexane-1,3-diones to Tautomerization Based on the Calculated Gibbs Free Energies. Energies, 13, 183. https://doi.org/10.3390/en13010183 
43. Du, L., Meng, Q., Jiang, H. and Li, Y. (2020) Using Evolutionary Information and Multi-Label Linear Discriminant Analysis to Predict the Subcellular Location of Multi-Site Bacterial Proteins via Chou's 5-Steps Rule. IEEE Access, 8, 56452-56461. https://doi.org/10.1109/ACCESS.2020.2982160

44. Dutta, A., Dalmia, A., R, A., Singh, K.K. and Anand, A. (2020) Using the Chou's 5-Steps Rule to Predict Splice Junctions with Interpretable Bidirectional Long Short-Term Memory Networks. Computers in Biology and Medicine, 116, Article ID: 103558. https://doi.org/10.1016/j.compbiomed.2019.103558

45. Ju, Z. and Wang, S.Y. (2020) Prediction of Lysine Formylation Sites Using the Composition of k-Spaced Amino Acid Pairs via Chou's 5-Steps Rule and General Pseudo Components. Genomics, 112, 859-866. https://doi.org/10.1016/j.ygeno.2019.05.027

46. Kabir, M., Ahmad, S., Iqbal, M. and Hayat, M. (2020) iNR-2L: A Two-Level Sequence-Based Predictor Developed via Chou's 5-Steps Rule and General PseAAC for Identifying Nuclear Receptors and Their Families. Genomics, 112, 276-285. https://doi.org/10.1016/j.ygeno.2019.02.006

47. Lin, W., Xiao, X., Qiu, W. and Chou, K.C. (2020) Use Chou's 5-Steps Rule to Predict Remote Homology Proteins by Merging Grey Incidence Analysis and Domain Similarity Analysis. Natural Science, 12, 181-198. https://doi.org/10.4236/ns.2020.123016

48. Vishnoi, S., Garg, P. and Arora, P. (2020) Physicochemical n-Grams Tool: A Tool for Protein Physicochemical Descriptor Generation via Chou's 5-Step Rule. Chemical Biology \& Drug Design, 95, 79-86.

https://doi.org/10.1111/cbdd.13617

49. Vundavilli, H., Datta, A., Sima, C., Hua, J., Lopes, R. and Bittner, M. (2020) Using Chou's 5-Steps Rule to Model Feedback in Lung Cancer IEEE Journal of Biomedical and Health Informatics, 21, 1-24. https://doi.org/10.1109/JBHI.2019.2958042

50. Yang, L., Lv, Y., Wang, S., Zhang, Q., Pan, Y., Su, D., Lu, Q. and Zuo, Y. (2020) Identifying FL11 Subtype by Characterizing Tumor Immune Microenvironment in Prostate Adenocarcinoma via Chou's 5-Steps Rule. Genomics, 112, 1500-1515. https://doi.org/10.1016/j.ygeno.2019.08.021

51. Chou, K.C. (2011) Some Remarks on Protein Attribute Prediction and Pseudo Amino Acid Composition (50th Anniversary Year Review, 5-Steps Rule). Journal of Theoretical Biology, 273, 236-247. https://doi.org/10.1016/j.jtbi.2010.12.024

52. Chou, K.C. and Shen, H.B. (2007) Recent Progresses in Protein Subcellular Location Prediction. Analytical Biochemistry, 370, 1-16. https://doi.org/10.1016/j.ab.2007.07.006

53. Chou, K.C. (2001) Prediction of Protein Cellular Attributes Using Pseudo Amino Acid Composition. PROTEINS: Structure, Function, and Genetics, 43, 246-255. (Erratum: ibid, 2001, Vol. 44, 60) https://doi.org/10.1002/prot.1035

54. Chou, K.C. (2005) Using Amphiphilic Pseudo Amino Acid Composition to Predict Enzyme Subfamily Classes. Bioinformatics, 21, 10-19. https://doi.org/10.1093/bioinformatics/bth466

55. Ding, Y.S. and Zhang, T.L. (2008) Using Chou's Pseudo Amino Acid Composition to Predict Subcellular Localization of Apoptosis Proteins: An Approach with Immune Genetic Algorithm-Based Ensemble Classifier. Pattern Recognition Letters, 29, 1887-1892. https://doi.org/10.1016/j.patrec.2008.06.007

56. Fang, Y., Guo, Y., Feng, Y. and Li, M. (2008) Predicting DNA-Binding Proteins: Approached from Chou's Pseudo Amino Acid Composition and Other Specific Sequence Features. Amino Acids, 34, 103-109. https://doi.org/10.1007/s00726-007-0568-2

57. Jiang, X., Wei, R., Zhang, T.L. and Gu, Q. (2008) Using the Concept of Chou's Pseudo Amino Acid Composition to Predict Apoptosis Proteins Subcellular Location: An Approach by Approximate Entropy. Protein \& Peptide Letters, 15, 392-396. https://doi.org/10.2174/092986608784246443 
58. Jiang, X., Wei, R., Zhao, Y. and Zhang, T. (2008) Using Chou's Pseudo Amino Acid Composition Based on Approximate Entropy and an Ensemble of AdaBoost Classifiers to Predict Protein Subnuclear Location. Amino Acids, 34, 669-675. https://doi.org/10.1007/s00726-008-0034-9

59. Li, F.M. and Li, Q.Z. (2008) Predicting Protein Subcellular Location Using Chou's Pseudo Amino Acid Composition and Improved Hybrid Approach. Protein \& Peptide Letters, 15, 612-616.

https://doi.org/10.2174/092986608784966930

60. Lin, H. (2008) The Modified Mahalanobis Discriminant for Predicting Outer Membrane Proteins by Using Chou's Pseudo Amino Acid Composition. Journal of Theoretical Biology, 252, 350-356.

https://doi.org/10.1016/j.jtbi.2008.02.004

61. Lin, H., Ding, H., Guo, F.B., Zhang, A.Y. and Huang, J. (2008) Predicting Subcellular Localization of Mycobacterial Proteins by Using Chou's Pseudo Amino Acid Composition. Protein \& Peptide Letters, 15, 739-744.

https://doi.org/10.2174/092986608785133681

62. Nanni, L. and Lumini, A. (2008) Genetic Programming for Creating Chou's Pseudo Amino Acid Based Features for Submitochondria Localization. Amino Acids, 34, 653-660. https://doi.org/10.1007/s00726-007-0018-1

63. Zhang, G.Y., Li, H.C., Gao, J.Q. and Fang, B.S. (2008) Predicting Lipase Types by Improved Chou's Pseudo Amino Acid Composition. Protein \& Peptide Letters, 15, 1132-1137.

https://doi.org/10.2174/092986608786071184

64. Zhang, S.W., Chen, W., Yang, F. and Pan, Q. (2008) Using Chou's Pseudo Amino Acid Composition to Predict Protein Quaternary Structure: A Sequence-Segmented PseAAC Approach. Amino Acids, 35, 591-598.

https://doi.org/10.1007/s00726-008-0086-x

65. Zhang, S.W., Zhang, Y.L., Yang, H.F., Zhao, C.H. and Pan, Q. (2008) Using the Concept of Chou's Pseudo Amino Acid Composition to Predict Protein Subcellular Localization: An Approach by Incorporating Evolutionary Information and Von Neumann Entropies. Amino Acids, 34, 565-572.

https://doi.org/10.1007/s00726-007-0010-9

66. Chen, C., Chen, L., Zou, X. and Cai, P. (2009) Prediction of Protein Secondary Structure Content by Using the Concept of Chou's Pseudo Amino Acid Composition and Support Vector Machine. Protein \& Peptide Letters, 16, 27-31. https://doi.org/10.2174/092986609787049420

67. Georgiou, D.N., Karakasidis, T.E., Nieto, J.J. and Torres, A. (2009) Use of Fuzzy Clustering Technique and Matrices to Classify Amino Acids and Its Impact to Chou's Pseudo Amino Acid Composition. Journal of Theoretical Biology, 257, 17-26. https://doi.org/10.1016/j.jtbi.2008.11.003

68. Li, Z.C., Zhou, X.B., Dai, Z. and Zou, X.Y. (2009) Prediction of Protein Structural Classes by Chou's Pseudo Amino Acid Composition: Approached Using Continuous Wavelet Transform and Principal Component Analysis. Amino Acids, 37, 415-425. https://doi.org/10.1007/s00726-008-0170-2

69. Lin, H., Wang, H., Ding, H., Chen, Y.L. and Li, Q.Z. (2009) Prediction of Subcellular Localization of Apoptosis Protein Using Chou's Pseudo Amino Acid Composition. Acta Biotheoretica, 57, 321-330.

https://doi.org/10.1007/s10441-008-9067-4

70. Qiu, J.D., Huang, J.H., Liang, R.P. and Lu, X.Q. (2009) Prediction of G-Protein-Coupled Receptor Classes Based on the Concept of Chou's Pseudo Amino Acid Composition: An Approach from Discrete Wavelet Transform. Analytical Biochemistry, 390, 68-73. https://doi.org/10.1016/j.ab.2009.04.009

71. Zeng, Y.H., Guo, Y.Z., Xiao, R.Q., Yang, L., Yu, L.Z. and Li, M.L. (2009) Using the Augmented Chou's Pseudo Amino Acid Composition for Predicting Protein Submitochondria Locations Based on Auto Covariance Approach. Journal of Theoretical Biology, 259, 366-372. https://doi.org/10.1016/j.jtbi.2009.03.028

72. Esmaeili, M., Mohabatkar, H. and Mohsenzadeh, S. (2010) Using the Concept of Chou's Pseudo Amino Acid 
Composition for Risk Type Prediction of Human Papillomaviruses. Journal of Theoretical Biology, 263, 203-209. https://doi.org/10.1016/j.jtbi.2009.11.016

73. Gu, Q., Ding, Y.S. and Zhang, T.L. (2010) Prediction of G-Protein-Coupled Receptor Classes in Low Homology Using Chou's Pseudo Amino Acid Composition with Approximate Entropy and Hydrophobicity Patterns. Protein \& Peptide Letters, 17, 559-567. https://doi.org/10.2174/092986610791112693

74. Mohabatkar, H. (2010) Prediction of Cyclin Proteins Using Chou's Pseudo Amino Acid Composition. Protein \& Peptide Letters, 17, 1207-1214. https://doi.org/10.2174/092986610792231564

75. Qiu, J.D., Huang, J.H., Shi, S.P. and Liang, R.P. (2010) Using the Concept of Chou's Pseudo Amino Acid Composition to Predict Enzyme Family Classes: An Approach with Support Vector Machine Based on Discrete Wavelet Transform. Protein \& Peptide Letters, 17, 715-722. https://doi.org/10.2174/092986610791190372

76. Sahu, S.S. and Panda, G. (2010) A Novel Feature Representation Method Based on Chou's Pseudo Amino Acid Composition for Protein Structural Class Prediction. Computational Biology and Chemistry, 34, 320-327. https://doi.org/10.1016/j.compbiolchem.2010.09.002

77. Yu, L., Guo, Y., Li, Y., Li, G., Li, M., Luo, J., Xiong, W. and Qin, W. (2010) SecretP: Identifying Bacterial Secreted Proteins by Fusing New Features into Chou's Pseudo Amino Acid Composition. Journal of Theoretical Biology, 267, 1-6. https://doi.org/10.1016/j.jtbi.2010.08.001

78. Guo, J., Rao, N., Liu, G., Yang, Y. and Wang, G. (2011) Predicting Protein Folding Rates Using the Concept of Chou’s Pseudo Amino Acid Composition. Journal of Computational Chemistry, 32, 1612-1617. https://doi.org/10.1002/jcc. 21740

79. Lin, J. and Wang, Y. (2011) Using a Novel AdaBoost Algorithm and Chou's Pseudo Amino Acid Composition for Predicting Protein Subcellular Localization. Protein \& Peptide Letters, 18, 1219-1225.

https://doi.org/10.2174/092986611797642797

80. Lin, J., Wang, Y. and Xu, X. (2011) A Novel Ensemble and Composite Approach for Classifying Proteins Based on Chou's Pseudo Amino Acid Composition. African Journal of Biotechnology, 10, 16963-16968.

https://doi.org/10.5897/AJB11.429

81. Mohabatkar, H., Mohammad Beigi, M. and Esmaeili, A. (2011) Prediction of GABA(A) Receptor Proteins Using the Concept of Chou's Pseudo Amino Acid Composition and Support Vector Machine. Journal of Theoretical Biology, 281, 18-23. https://doi.org/10.1016/j.jtbi.2011.04.017

82. Mohammad, B.M., Behjati, M. and Mohabatkar, H. (2011) Prediction of Metalloproteinase Family Based on the Concept of Chou's Pseudo Amino Acid Composition Using a Machine Learning Approach. Journal of Structural and Functional Genomics, 12, 191-197. https://doi.org/10.1007/s10969-011-9120-4

83. Qiu, J.D., Suo, S.B., Sun, X.Y., Shi, S.P. and Liang, R.P. (2011) OligoPred: A Web-Server for Predicting Homo-Oligomeric Proteins by Incorporating Discrete Wavelet Transform into Chou's Pseudo Amino Acid Composition. Journal of Molecular Graphics \& Modelling, 30, 129-134. https://doi.org/10.1016/j.jmgm.2011.06.014

84. Zou, D., He, Z., He, J. and Xia, Y. (2011) Supersecondary Structure Prediction Using Chou's Pseudo Amino Acid Composition. Journal of Computational Chemistry, 32, 271-278. https://doi.org/10.1002/jcc.21616

85. Cao, J.Z., Liu, W.Q. and Gu, H. (2012) Predicting Viral Protein Subcellular Localization with Chou's Pseudo Amino Acid Composition and Imbalance-Weighted Multi-Label K-Nearest Neighbor Algorithm. Protein and Peptide Letters, 19, 1163-1169. https://doi.org/10.2174/092986612803216999

86. Chen, C., Shen, Z.B. and Zou, X.Y. (2012) Dual-Layer Wavelet SVM for Predicting Protein Structural Class via the General Form of Chou's Pseudo Amino Acid Composition. Protein \& Peptide Letters, 19, 422-429. https://doi.org/10.2174/092986612799789332

87. Du, P., Wang, X., Xu, C. and Gao, Y. (2012) PseAAC-Builder: A Cross-Platform Stand-Alone Program for Ge- 
nerating Various Special Chou's Pseudo Amino Acid Compositions. Analytical Biochemistry, 425, 117-119. https://doi.org/10.1016/j.ab.2012.03.015

88. Fan, G.L. and Li, Q.Z. (2012) Predict Mycobacterial Proteins Subcellular Locations by Incorporating Pseudo-Average Chemical Shift into the General form of Chou's Pseudo Amino Acid Composition. Journal of Theoretical Biology, 304, 88-95. https://doi.org/10.1016/j.jtbi.2012.03.017

89. Fan, G.L. and Li, Q.Z. (2012) Predicting Protein Submitochondria Locations by Combining Different Descriptors into the General Form of Chou's Pseudo Amino Acid Composition. Amino Acids, 43, 545-555. https://doi.org/10.1007/s00726-011-1143-4

90. Li, L.Q., Zhang, Y., Zou, L.Y., Zhou, Y. and Zheng, X.Q. (2012) Prediction of Protein Subcellular Multi-Localization Based on the General form of Chou's Pseudo Amino Acid Composition. Protein \& Peptide Letters, 19, 375-387. https://doi.org/10.2174/092986612799789369

91. Liu, L., Hu, X.Z., Liu, X.X., Wang, Y. and Li, S.B. (2012) Predicting Protein Fold Types by the General Form of Chou's Pseudo Amino Acid Composition: Approached from Optimal Feature Extractions. Protein \& Peptide Letters, 19, 439-449. https://doi.org/10.2174/092986612799789378

92. Nanni, L., Brahnam, S. and Lumini, A. (2012) Wavelet Images and Chou's Pseudo Amino Acid Composition for Protein Classification. Amino Acids, 43, 657-665. https://doi.org/10.1007/s00726-011-1114-9

93. Nanni, L., Lumini, A., Gupta, D. and Garg, A. (2012) Identifying Bacterial Virulent Proteins by Fusing a Set of Classifiers Based on Variants of Chou's Pseudo Amino Acid Composition and on Evolutionary Information. IEEE-ACM Transaction on Computational Biolology and Bioinformatics, 9, 467-475. https://doi.org/10.1109/TCBB.2011.117

94. Niu, X.H., Hu, X.H., Shi, F. and Xia, J.B. (2012) Predicting Protein Solubility by the General Form of Chou's Pseudo Amino Acid Composition: Approached from Chaos Game Representation and Fractal Dimension. Protein \& Peptide Letters, 19, 940-948. https://doi.org/10.2174/092986612802084492

95. Ren, L.Y., Zhang, Y.S. and Gutman, I. (2012) Predicting the Classification of Transcription Factors by Incorporating Their Binding Site Properties into a Novel Mode of Chou's Pseudo Amino Acid Composition. Protein \& Peptide Letters, 19, 1170-1176. https://doi.org/10.2174/092986612803217088

96. Zhao, X.W., Ma, Z.Q. and Yin, M.H. (2012) Predicting Protein-Protein Interactions by Combing Various Sequence-Derived Features into the General Form of Chou's Pseudo Amino Acid Composition. Protein \& Peptide Letters, 19, 492-500. https://doi.org/10.2174/092986612800191080

97. Zia-ur-Rehman, K.A. (2012) Identifying GPCRs and Their Types with Chou's Pseudo Amino Acid Composition: An Approach from Multi-Scale Energy Representation and Position Specific Scoring Matrix. Protein \& Peptide Letters, 19, 890-903. https://doi.org/10.2174/092986612801619589

98. Chen, Y.K. and Li, K.B. (2013) Predicting Membrane Protein Types by Incorporating Protein Topology, Domains, Signal Peptides, and Physicochemical Properties into the General Form of Chou's Pseudo Amino Acid Composition. Journal of Theoretical Biology, 318, 1-12. https://doi.org/10.1016/j.jtbi.2012.10.033

99. Fan, G.L. and Li, Q.Z. (2013) Discriminating Bioluminescent Proteins by Incorporating Average Chemical Shift and Evolutionary Information into the General Form of Chou's Pseudo Amino Acid Composition. Journal of Theoretical Biology, 334, 45-51. https://doi.org/10.1016/j.jtbi.2013.06.003

100. Georgiou, D.N., Karakasidis, T.E. and Megaritis, A.C. (2013) A Short Survey on Genetic Sequences, Chou's Pseudo Amino Acid Composition and Its Combination with Fuzzy Set Theory. The Open Bioinformatics Journal, 7, 41-48. https://doi.org/10.2174/1875036201307010041

101. Gupta, M.K., Niyogi, R. and Misra, M. (2013) An Alignment-Free Method to Find Similarity among Protein Sequences via the General Form of Chou's Pseudo Amino Acid Composition. SAR and QSAR in Environmental 
Research, 24, 597-609. https://doi.org/10.1080/1062936X.2013.773378

102. Huang, C. and Yuan, J. (2013) Using Radial Basis Function on the General Form of Chou's Pseudo Amino Acid Composition and PSSM to Predict Subcellular Locations of Proteins with Both Single and Multiple Sites. Biosystems, 113, 50-57. https://doi.org/10.1016/j.biosystems.2013.04.005

103. Huang, C. and Yuan, J.Q. (2013) A Multilabel Model Based on Chou's Pseudo Amino Acid Composition for Identifying Membrane Proteins with Both Single and Multiple Functional Types. The Journal of Membrane Biology, 246, 327-334. https://doi.org/10.1007/s00232-013-9536-9

104. Huang, C. and Yuan, J.Q. (2013) Predicting Protein Subchloroplast Locations with Both Single and Multiple Sites via Three Different Modes of Chou's Pseudo Amino Acid Compositions. Journal of Theoretical Biology, 335, 205-212. https://doi.org/10.1016/j.jtbi.2013.06.034

105. Khosravian, M., Faramarzi, F.K., Beigi, M.M., Behbahani, M. and Mohabatkar, H. (2013) Predicting Antibacterial Peptides by the Concept of Chou's Pseudo Amino Acid Composition and Machine Learning Methods. Protein \& Peptide Letters, 20, 180-186. https://doi.org/10.2174/092986613804725307

106. Lin, H., Ding, C., Yuan, L.-F., Chen, W., Ding, H., Li, Z.-Q., Guo, F.-B., Huang, J. and Rao, N.-N. (2013) Predicting Subchloroplast Locations of Proteins Based on the General Form of Chou's Pseudo Amino Acid Composition: Approached from Optimal Tripeptide Composition. International Journal of Biomethmatics, 6, Article ID: 1350003. https://doi.org/10.1142/S1793524513500034

107. Liu, B., Wang, X., Zou, Q., Dong, Q. and Chen, Q. (2013) Protein Remote Homology Detection by Combining Chou's Pseudo Amino Acid Composition and Profile-Based Protein Representation. Molecular Informatics, 32, 775-782. https://doi.org/10.1002/minf.201300084

108. Mohabatkar, H., Beigi, M.M., Abdolahi, K. and Mohsenzadeh, S. (2013) Prediction of Allergenic Proteins by Means of the Concept of Chou's Pseudo Amino Acid Composition and a Machine Learning Approach. Medicinal Chemistry, 9, 133-137. https://doi.org/10.2174/157340613804488341

109. Qin, Y.F., Zheng, L. and Huang, J. (2013) Locating Apoptosis Proteins by Incorporating the Signal Peptide Cleavage Sites into the General Form of Chou's Pseudo Amino Acid Composition. International Journal of Quantum Chemistry, 113, 1660-1667. https://doi.org/10.1002/qua.24383

110. Sarangi, A.N., Lohani, M. and Aggarwal, R. (2013) Prediction of Essential Proteins in Prokaryotes by Incorporating Various Physico-Chemical Features into the General Form of Chou's Pseudo Amino Acid Composition. Protein \& Peptide Letters, 20, 781-795. https://doi.org/10.2174/0929866511320070008

111. Wan, S., Mak, M.W. and Kung, S.Y. (2013) GOASVM: A Subcellular Location Predictor by Incorporating Term-Frequency Gene Ontology into the General Form of Chou's Pseudo Amino Acid Composition. Journal of Theoretical Biology, 323, 40-48. https://doi.org/10.1016/j.jtbi.2013.01.012

112. Wang, X., Li, G.Z. and Lu, W.C. (2013) Virus-ECC-mPLoc: A Multi-Label Predictor for Predicting the Subcellular Localization of Virus Proteins with Both Single and Multiple Sites Based on a General Form of Chou's Pseudo Amino Acid Composition. Protein \& Peptide Letters, 20, 309-317. https://doi.org/10.2174/092986613804910608

113. Niu, X.H., et al. (2013) Using the Concept of Chou's Pseudo Amino Acid Composition to Predict Protein Solubility: An Approach with Entropies in Information Theory. Journal of Theoretical Biology, 332, 211-217. https://doi.org/10.1016/j.jtbi.2013.03.010

114. Du, P., Gu, S. and Jiao, Y. (2014) PseAAC-General: Fast Building Various Modes of General Form of Chou's Pseudo Amino Acid Composition for Large-Scale Protein Datasets. International Journal of Molecular Sciences, 15, 3495-3506. https://doi.org/10.3390/ijms15033495

115. Hajisharifi, Z., Piryaiee, M., Mohammad Beigi, M., Behbahani, M. and Mohabatkar, H. (2014) Predicting Anti- 
cancer Peptides with Chou's Pseudo Amino Acid Composition and Investigating Their Mutagenicity via Ames Test. Journal of Theoretical Biology, 341, 34-40. https://doi.org/10.1016/j.jtbi.2013.08.037

116. Jia, C., Lin, X. and Wang, Z. (2014) Prediction of Protein S-Nitrosylation Sites Based on Adapted Normal Distribution Bi-Profile Bayes and Chou's Pseudo Amino Acid Composition. International Journal of Molecular Sciences, 15, 10410-10423. https://doi.org/10.3390/ijms150610410

117. Kong, L., Zhang, L. and Lv, J. (2014) Accurate Prediction of Protein Structural Classes by Incorporating Predicted Secondary Structure Information into the General form of Chou's Pseudo Amino Acid Composition. Journal of Theoretical Biology, 344, 12-18. https://doi.org/10.1016/j.jtbi.2013.11.021

118. Nanni, L., Brahnam, S. and Lumini, A. (2014) Prediction of Protein Structure Classes by Incorporating Different Protein Descriptors into General Chou's Pseudo Amino Acid Composition. Journal of Theoretical Biology, 360, 109-116. https://doi.org/10.1016/j.jtbi.2014.07.003

119. Zhang, J., Sun, P., Zhao, X. and Ma, Z. (2014) PECM: Prediction of Extracellular Matrix Proteins Using the Concept of Chou's Pseudo Amino Acid Composition. Journal of Theoretical Biology, 363, 412-418. https://doi.org/10.1016/j.jtbi.2014.08.002

120. Zhang, L., Zhao, X. and Kong, L. (2014) Predict Protein Structural Class for Low-Similarity Sequences by Evolutionary Difference Information into the General Form of Chou's Pseudo Amino Acid Composition. Journal of Theoretical Biology, 355, 105-110. https://doi.org/10.1016/j.jtbi.2014.04.008

121. Zuo, Y.C., Peng, Y., Liu, L., Chen, W., Yang, L. and Fan, G.L. (2014) Predicting Peroxidase Subcellular Location by Hybridizing Different Descriptors of Chou's Pseudo Amino Acid Patterns. Analytical Biochemistry, 458, 14-19. https://doi.org/10.1016/j.ab.2014.04.032

122. Ali, F. and Hayat, M. (2015) Classification of Membrane Protein Types Using Voting Feature Interval in Combination with Chou's Pseudo Amino Acid Composition. Journal of Theoretical Biology, 384, 78-83. https://doi.org/10.1016/j.jtbi.2015.07.034

123. Fan, G.L., Zhang, X.Y., Liu, Y.L., Nang, Y. and Wang, H. (2015) DSPMP: Discriminating Secretory Proteins of Malaria Parasite by Hybridizing Different Descriptors of Chou's Pseudo Amino Acid Patterns. Journal of Computational Chemistry, 36, 2317-2327. https://doi.org/10.1002/jcc.24210

124. Huang, C. and Yuan, J.Q. (2015) Simultaneously Identify Three Different Attributes of Proteins by Fusing Their Three Different Modes of Chou's Pseudo Amino Acid Compositions. Protein \& Peptide Letters, 22, 547-556. https://doi.org/10.2174/0929866522666150209151344

125. Khan, Z.U., Hayat, M. and Khan, M.A. (2015) Discrimination of Acidic and Alkaline Enzyme Using Chou's Pseudo Amino Acid Composition in Conjunction with Probabilistic Neural Network Model. Journal of Theoretical Biology, 365, 197-203. https://doi.org/10.1016/j.jtbi.2014.10.014

126. Kumar, R., Srivastava, A., Kumari, B. and Kumar, M. (2015) Prediction of Beta-Lactamase and Its Class by Chou's Pseudo Amino Acid Composition and Support Vector Machine. Journal of Theoretical Biology, 365, 96-103. https://doi.org/10.1016/j.jtbi.2014.10.008

127. Wang, X., Zhang, W., Zhang, Q. and Li, G.Z. (2015) MultiP-SChlo: Multi-Label Protein Subchloroplast Localization Prediction with Chou's Pseudo Amino Acid Composition and a Novel Multi-Label Classifier. Bioinformatics, 31, 2639-2645. https://doi.org/10.1093/bioinformatics/btv212

128. Jiao, Y.S. and Du, P.F. (2016) Prediction of Golgi-Resident Protein Types Using General Form of Chou's Pseudo Amino Acid Compositions: Approaches with Minimal Redundancy Maximal Relevance Feature Selection. Journal of Theoretical Biology, 402, 38-44. https://doi.org/10.1016/j.jtbi.2016.04.032

129. Tang, H., Chen, W. and Lin, H. (2016) Identification of Immunoglobulins Using Chou's Pseudo Amino Acid Composition with Feature Selection Technique. Molecular BioSystems, 12, 1269-1275. 
https://doi.org/10.1039/C5MB00883B

130. Zou, H.L. and Xiao, X. (2016) Predicting the Functional Types of Singleplex and Multiplex Eukaryotic Membrane Proteins via Different Models of Chou's Pseudo Amino Acid Compositions. The Journal of Membrane Biology, 249, 23-29. https://doi.org/10.1007/s00232-015-9830-9

131. Rahimi, M., Bakhtiarizadeh, M.R. and Mohammadi-Sangcheshmeh, A. (2017) OOgenesis_Pred: A Sequence-Based Method for Predicting Oogenesis Proteins by Six Different Modes of Chou's Pseudo Amino Acid Composition. Journal of Theoretical Biology, 414, 128-136. https://doi.org/10.1016/j.jtbi.2016.11.028

132. Tripathi, P. and Pandey, P.N. (2017) A Novel Alignment-Free Method to Classify Protein Folding Types by Combining Spectral Graph Clustering with Chou's Pseudo Amino Acid Composition. Journal of Theoretical Biology, 424, 49-54. https://doi.org/10.1016/j.jtbi.2017.04.027

133. Yu, B., Lou, L., Li, S., Zhang, Y., Qiu, W., Wu, X., Wang, M. and Tian, B. (2017) Prediction of Protein Structural Class for Low-Similarity Sequences Using Chou's Pseudo Amino Acid Composition and Wavelet Denoising. Journal of Molecular Graphics and Modelling, 76, 260-273. https://doi.org/10.1016/j.jmgm.2017.07.012

134. Arif, M., Hayat, M. and Jan, Z. (2018) iMem-2LSAAC: A Two-Level Model for Discrimination of Membrane Proteins and Their Types by Extending the Notion of SAAC into Chou's Pseudo Amino Acid Composition. Journal of Theoretical Biology, 442, 11-21. https://doi.org/10.1016/j.jtbi.2018.01.008

135. Mei, J. and Zhao, J. (2018) Prediction of HIV-1 and HIV-2 Proteins by Using Chou's Pseudo Amino Acid Compositions and Different Classifiers. Scientific Reports, 8, Article No. 2359.

https://doi.org/10.1038/s41598-018-20819-x

136. Nosrati, M., Mohabatkar, H. and Behbahani, M. (2019) Introducing of an Integrated Artificial Neural Network and Chou's Pseudo Amino Acid Composition Approach for Computational Epitope-Mapping of Crimean-Congo Haemorrhagic Fever Virus Antigens. International Immunopharmacology.

https://doi.org/10.1016/j.intimp.2019.106020

https://www.sciencedirect.com/science/article/pii/S1567576919321277

137. Nosrati, M., Mohabatkar, H. and Behbahani, M. (2020) Introducing of an Integrated Artificial Neural Network and Chou's Pseudo Amino Acid Composition Approach for Computational Epitope-Mapping of Crimean-Congo Haemorrhagic Fever Virus Antigens. International Immunopharmacology, 78, Article ID: 106020. https://doi.org/10.1016/j.intimp.2019.106020

138. Hayat, M. and Khan, A. (2012) Discriminating Outer Membrane Proteins with Fuzzy K-Nearest Neighbor Algorithms Based on the General Form of Chou's PseAAC. Protein \& Peptide Letters, 19, 411-421. https://doi.org/10.2174/092986612799789387

139. Liao, B., Xiang, Q. and Li, D. (2012) Incorporating Secondary Features into the General Form of Chou's PseAAC for Predicting Protein Structural Class. Protein \& Peptide Letters, 19, 1133-1138. https://doi.org/10.2174/092986612803217051

140. Mei, S. (2012) Multi-Kernel Transfer Learning Based on Chou's PseAAC Formulation for Protein Submitochondria Localization. Journal of Theoretical Biology, 293, 121-130. https://doi.org/10.1016/j.jtbi.2011.10.015

141. Mei, S. (2012) Predicting Plant Protein Subcellular Multi-Localization by Chou's PseAAC Formulation Based Multi-Label Homolog Knowledge Transfer Learning. Journal of Theoretical Biology, 310, 80-87. https://doi.org/10.1016/j.jtbi.2012.06.028

142. Qin, Y.F., Wang, C.H., Yu, X.Q., Zhu, J., Liu, T.G. and Zheng, X.Q. (2012) Predicting Protein Structural Class by Incorporating Patterns of Over-Represented k-Mers into the General Form of Chou's PseAAC. Protein \& Peptide Letters, 19, 388-397. https://doi.org/10.2174/092986612799789350

143. Sun, X.Y., Shi, S.P., Qiu, J.D., Suo, S.B., Huang, S.Y. and Liang, R.P. (2012) Identifying Protein Quaternary 
Structural Attributes by Incorporating Physicochemical Properties into the General Form of Chou's PseAAC via Discrete Wavelet Transform. Molecular BioSystems, 8, 3178-3184. https://doi.org/10.1039/c2mb25280e

144. Cao, D.S., Xu, Q.S. and Liang, Y.Z. (2013) Propy: A Tool to Generate Various Modes of Chou's PseAAC. Bioinformatics, 29, 960-962. https://doi.org/10.1093/bioinformatics/btt072

145. Chang, T.H., Wu, L.C., Lee, T.Y., Chen, S.P., Huang, H.D. and Horng, J.T. (2013) EuLoc: A Web-Server for Accurately Predict Protein Subcellular Localization in Eukaryotes by Incorporating Various Features of Sequence Segments into the General Form of Chou's PseAAC. Journal of Computer-Aided Molecular Design, 27, 91-103. https://doi.org/10.1007/s10822-012-9628-0

146. Fan, G.-L., Li, Q.-Z. and Zuo, Y.-C. (2013) Predicting Acidic and Alkaline Enzymes by Incorporating the Average Chemical Shift and Gene Ontology Informations into the General Form of Chou's PseAAC. Process Biochemistry, 48, 1048-1053. https://doi.org/10.1016/j.procbio.2013.05.012

147. Pacharawongsakda, E. and Theeramunkong, T. (2013) Predict Subcellular Locations of Singleplex and Multiplex Proteins by Semi-Supervised Learning and Dimension-Reducing General Mode of Chou's PseAAC. IEEE Transactions on Nanobioscience, 12, 311-320. https://doi.org/10.1109/TNB.2013.2272014

148. Xie, H.L., Fu, L. and Nie, X.D. (2013) Using Ensemble SVM to Identify Human GPCRs N-Linked Glycosylation Sites Based on the General Form of Chou's PseAAC. Protein Engineering, Design and Selection, 26, 735-742. https://doi.org/10.1093/protein/gzt042

149. Han, G.S., Yu, Z.G. and Anh, V. (2014) A Two-Stage SVM Method to Predict Membrane Protein Types by Incorporating Amino Acid Classifications and Physicochemical Properties into a General Form of Chou's PseAAC. Journal of Theoretical Biology, 344, 31-39. https://doi.org/10.1016/j.jtbi.2013.11.017

150. Li, L., Yu, S., Xiao, W., Li, Y., Li, M., Huang, L., Zheng, X., Zhou, S. and Yang, H. (2014) Prediction of Bacterial Protein Subcellular Localization by Incorporating Various Features into Chou's PseAAC and a Backward Feature Selection Approach. Biochimie, 104, 100-107. https://doi.org/10.1016/j.biochi.2014.06.001

151. Zhang, J., Zhao, X., Sun, P. and Ma, Z. (2014) PSNO: Predicting Cysteine S-Nitrosylation Sites by Incorporating Various Sequence-Derived Features into the General Form of Chou's PseAAC. International Journal of Molecular Sciences, 15, 11204-11219. https://doi.org/10.3390/ijms150711204

152. Liu, B., Xu, J., Fan, S., Xu, R., Zhou, J. and Wang, X. (2015) PseDNA-Pro: DNA-Binding Protein Identification by Combining Chou's PseAAC and Physicochemical Distance Transformation. Molecular Informatics, 34, 8-17. https://doi.org/10.1002/minf.201400025

153. Mandal, M., Mukhopadhyay, A. and Maulik, U. (2015) Prediction of Protein Subcellular Localization by Incorporating Multiobjective PSO-Based Feature Subset Selection into the General Form of Chou's PseAAC. Medical \& Biological Engineering \& Computing, 53, 331-344. https://doi.org/10.1007/s11517-014-1238-7

154. Sanchez, V., Peinado, A.M., Perez-Cordoba, J.L. and Gomez, A.M. (2015) A New Signal Characterization and Signal-Based Chou's PseAAC Representation of Protein Sequences. Journal of Bioinformatics and Computational Biology, 13, Article ID: 1550024. https://doi.org/10.1142/S0219720015500249

155. Kabir, M. and Hayat, M. (2016) iRSpot-GAEnsC: Identifying Recombination Spots via Ensemble Classifier and Extending the Concept of Chou's PseAAC to Formulate DNA Samples. Molecular Genetics and Genomics, 291, 285-296. https://doi.org/10.1007/s00438-015-1108-5

156. Tahir, M. and Hayat, M. (2016) iNuc-STNC: A Sequence-Based Predictor for Identification of Nucleosome Positioning in Genomes by Extending the Concept of SAAC and Chou's PseAAC. Molecular BioSystems, 12, 2587-2593. https://doi.org/10.1039/C6MB00221H

157. Ju, Z. and He, J.J. (2017) Prediction of Lysine Propionylation Sites Using Biased SVM and Incorporating Four Different Sequence Features into Chou's PseAAC. Journal of Molecular Graphics and Modelling, 76, 356-363. 
https://doi.org/10.1016/j.jmgm.2017.07.022

158. Yu, B., Li, S., Qiu, W.Y., Chen, C., Chen, R.X., Wang, L., Wang, M.H. and Zhang, Y. (2017) Accurate Prediction of Subcellular Location of Apoptosis Proteins Combining Chou's PseAAC and PsePSSM Based on Wavelet Denoising. Oncotarget, 8, 107640-107665. https://doi.org/10.18632/oncotarget.22585

159. Ahmad, J. and Hayat, M. (2018) MFSC: Multi-Voting Based Feature Selection for Classification of Golgi Proteins by Adopting the General Form of Chou's PseAAC Components. Journal of Theoretical Biology, 463, 99-109. https://doi.org/10.1016/j.jtbi.2018.12.017

160. Akbar, S. and Hayat, M. (2018) iMethyl-STTNC: Identification of N(6)-methyladenosine Sites by Extending the Idea of SAAC into Chou's PseAAC to Formulate RNA Sequences. Journal of Theoretical Biology, 455, 205-211. https://doi.org/10.1016/j.jtbi.2018.07.018

161. Contreras-Torres, E. (2018) Predicting Structural Classes of Proteins by Incorporating Their Global and Local Physicochemical and Conformational Properties into General Chou's PseAAC. Journal of Theoretical Biology, 454, 139-145. https://doi.org/10.1016/j.jtbi.2018.05.033

162. Fu, X., Zhu, W., Liso, B., Cai, L., Peng, L. and Yang, J. (2018) Improved DNA-Binding Protein Identification by Incorporating Evolutionary Information into the Chou's PseAAC. IEEE Access, 20. https://doi.org/10.1109/ACCESS.2018.2876656

163. Javed, F. and Hayat, M. (2018) Predicting Subcellular Localizations of Multi-Label Proteins by Incorporating the Sequence Features into Chou's PseAAC. Genomics. https://doi.org/10.1016/j.ygeno.2018.09.004

164. Mousavizadegan, M. and Mohabatkar, H. (2018) Computational Prediction of Antifungal Peptides via Chou's PseAAC and SVM. Journal of Bioinformatics and Computational Biology, 16, Article ID: 1850016. https://doi.org/10.1142/S0219720018500166

165. Zhang, S. and Liang, Y. (2018) Predicting Apoptosis Protein Subcellular Localization by Integrating Auto-Cross Correlation and PSSM into Chou's PseAAC. Journal of Theoretical Biology, 457, 163-169.

https://doi.org/10.1016/j.jtbi.2018.08.042

166. Ahmad, J. and Hayat, M. (2019) MFSC: Multi-Voting Based Feature Selection for Classification of Golgi Proteins by Adopting the General Form of Chou's PseAAC Components. Journal of Theoretical Biology, 463, 99-109. https://doi.org/10.1016/j.jtbi.2018.12.017

167. Butt, A.H., Rasool, N. and Khan, Y.D. (2019) Prediction of Antioxidant Proteins by Incorporating Statistical Moments Based Features into Chou's PseAAC. Journal of Theoretical Biology, 473, 1-8.

https://doi.org/10.1016/j.jtbi.2019.04.019

168. Javed, F. and Hayat, M. (2019) Predicting Subcellular Localization of Multi-Label Proteins by Incorporating the Sequence Features into Chou's PseAAC. Genomics, 111, 1325-1332. https://doi.org/10.1016/j.ygeno.2018.09.004

169. Tahir, M., Hayat, M. and Khan, S.A. (2019) iNuc-ext-PseTNC: An Efficient Ensemble Model for Identification of Nucleosome Positioning by Extending the Concept of Chou's PseAAC to Pseudo-Tri-Nucleotide Composition. Molecular Genetics and Genomics: MGG, 294, 199-210. https://doi.org/10.1007/s00438-018-1498-2

170. Hayat, M. and Iqbal, N. (2014) Discriminating Protein Structure Classes by Incorporating Pseudo Average Chemical Shift to Chou's General PseAAC and Support Vector Machine. Computer Methods and Programs in Biomedicine, 116, 184-192. https://doi.org/10.1016/j.cmpb.2014.06.007

171. Ahmad, S., Kabir, M. and Hayat, M. (2015) Identification of Heat Shock Protein Families and J-Protein Types by Incorporating Dipeptide Composition into Chou's General PseAAC. Computer Methods and Programs in Biomedicine, 122, 165-174. https://doi.org/10.1016/j.cmpb.2015.07.005

172. Dehzangi, A., Heffernan, R., Sharma, A., Lyons, J., Paliwal, K. and Sattar, A. (2015) Gram-Positive and Gram-Negative Protein Subcellular Localization by Incorporating Evolutionary-Based Descriptors into Chou's 
General PseAAC. Journal of Theoretical Biology, 364, 284-294. https://doi.org/10.1016/j.jtbi.2014.09.029

173. Sharma, R., Dehzangi, A., Lyons, J., Paliwal, K., Tsunoda, T. and Sharma, A. (2015) Predict Gram-Positive and Gram-Negative Subcellular Localization via Incorporating Evolutionary Information and Physicochemical Features Into Chou's General PseAAC. IEEE Transactions on NanoBioscience, 14, 915-926. https://doi.org/10.1109/TNB.2015.2500186

174. Zhang, M., Zhao, B. and Liu, X. (2015) Predicting Industrial Polymer Melt Index via Incorporating Chaotic Characters into Chou's General PseAAC. Chemometrics and Intelligent Laboratory Systems (CHEMOLAB), 146, 232-240. https://doi.org/10.1016/j.chemolab.2015.05.028

175. Zhang, S.L. (2015) Accurate Prediction of Protein Structural Classes by Incorporating PSSS and PSSM into Chou's General PseAAC. Chemometrics and Intelligent Laboratory Systems (CHEMOLAB), 142, 28-35. https://doi.org/10.1016/j.chemolab.2015.01.004

176. Ahmad, K., Waris, M. and Hayat, M. (2016) Prediction of Protein Submitochondrial Locations by Incorporating Dipeptide Composition into Chou's General Pseudo Amino Acid Composition. The Journal of Membrane Biology, 249, 293-304. https://doi.org/10.1007/s00232-015-9868-8

177. Behbahani, M., Mohabatkar, H. and Nosrati, M. (2016) Analysis and Comparison of Lignin Peroxidases between Fungi and Bacteria Using Three Different Modes of Chou's General Pseudo Amino Acid Composition. Journal of Theoretical Biology, 411, 1-5. https://doi.org/10.1016/j.jtbi.2016.09.001

178. Fan, G.L., Liu, Y.L. and Wang, H. (2016) Identification of Thermophilic Proteins by Incorporating Evolutionary and Acid Dissociation Information into Chou's General Pseudo Amino Acid Composition. Journal of Theoretical Biology, 407, 138-142. https://doi.org/10.1016/j.jtbi.2016.07.010

179. Ju, Z., Cao, J.Z. and Gu, H. (2016) Predicting Lysine Phosphoglycerylation with Fuzzy SVM by Incorporating k-Spaced Amino Acid Pairs into Chou's General PseAAC. Journal of Theoretical Biology, 397, 145-150. https://doi.org/10.1016/j.jtbi.2016.02.020

180. Tiwari, A.K. (2016) Prediction of G-Protein Coupled Receptors and Their Subfamilies by Incorporating Various Sequence Features into Chou's General PseAAC. Computer Methods and Programs in Biomedicine, 134, 197-213. https://doi.org/10.1016/j.cmpb.2016.07.004

181. Xu, C., Sun, D., Liu, S. and Zhang, Y. (2016) Protein Sequence Analysis by Incorporating Modified Chaos Game and Physicochemical Properties into Chou's General Pseudo Amino Acid Composition. Journal of Theoretical Biology, 406, 105-115. https://doi.org/10.1016/j.jtbi.2016.06.034

182. Zou, H.L. and Xiao, X. (2016) Classifying Multifunctional Enzymes by Incorporating Three Different Models into Chou's General Pseudo Amino Acid Composition. The Journal of Membrane Biology, 249, 561-567. https://doi.org/10.1007/s00232-016-9904-3

183. Jiao, Y.S. and Du, P.F. (2017) Predicting Protein Submitochondrial Locations by Incorporating the Positional-Specific Physicochemical Properties into Chou's General Pseudo-Amino Acid Compositions. Journal of Theoretical Biology, 416, 81-87. https://doi.org/10.1016/j.jtbi.2016.12.026

184. Ju, Z. and He, J.J. (2017) Prediction of Lysine Crotonylation Sites by Incorporating the Composition of k-Spaced Amino Acid Pairs into Chou's General PseAAC. Journal of Molecular Graphics and Modelling, 77, 200-204. https://doi.org/10.1016/j.jmgm.2017.08.020

185. Khan, M., Hayat, M., Khan, S.A. and Iqbal, N. (2017) Unb-DPC: Identify Mycobacterial Membrane Protein Types by Incorporating Un-Biased Dipeptide Composition into Chou's General PseAAC. Journal of Theoretical Biology, 415, 13-19. https://doi.org/10.1016/j.jtbi.2016.12.004

186. Liang, Y. and Zhang, S. (2017) Predict Protein Structural Class by Incorporating Two Different Modes of Evolutionary Information into Chou's General Pseudo Amino Acid Composition. Journal of Molecular Graphics and 
Modelling, 78, 110-117. https://doi.org/10.1016/j.jmgm.2017.10.003

187. Meher, P.K., Sahu, T.K., Saini, V. and Rao, A.R. (2017) Predicting Antimicrobial Peptides with Improved Accuracy by Incorporating the Compositional, Physico-Chemical and Structural Features into Chou's General PseAAC. Scientific Reports, 7, Article No. 42362. https://doi.org/10.1038/srep42362

188. Qiu, W.R., Zheng, Q.S., Sun, B.Q. and Xiao, X. (2017) Multi-iPPseEvo: A Multi-Label Classifier for Identifying Human Phosphorylated Proteins by Incorporating Evolutionary Information into Chou's General PseAAC via Grey System Theory. Molecular Informatics, 36, UNSP 1600085. https://doi.org/10.1002/minf.201600085

189. Xu, C., Ge, L., Zhang, Y., Dehmer, M. and Gutman, I. (2017) Prediction of Therapeutic Peptides by Incorporating q-Wiener Index into Chou's General PseAAC. Journal of Biomedical Informatics. https://doi.org/10.1016/j.jbi.2017.09.011

190. Butt, A.H., Rasool, N. and Khan, Y.D. (2018) Predicting Membrane Proteins and Their Types by Extracting Various Sequence Features into Chou's General PseAAC. Molecular Biology Reports. https://doi.org/10.1007/s11033-018-4391-5

191. Ghauri, A.W., Khan, Y.D., Rasool, N., Khan, S.A. and Chou, K.C. (2018) pNitro-Tyr-PseAAC: Predict Nitrotyrosine Sites in Proteins by Incorporating Five Features into Chou's General PseAAC. Current Pharmaceutical Design, 24, 4034-4043. https://doi.org/10.2174/1381612825666181127101039

192. Ju, Z. and Wang, S.Y. (2018) Prediction of Citrullination Sites by Incorporating k-Spaced Amino Acid Pairs into Chou's General Pseudo Amino Acid Composition. Gene, 664, 78-83. https://doi.org/10.1016/j.gene.2018.04.055

193. Krishnan, M.S. (2018) Using Chou's General PseAAC to Analyze the Evolutionary Relationship of Receptor Associated Proteins (RAP) with Various Folding Patterns of Protein Domains. Journal of Theoretical Biology, 445, 62-74. https://doi.org/10.1016/j.jtbi.2018.02.008

194. Liang, Y. and Zhang, S. (2018) Identify Gram-Negative Bacterial Secreted Protein Types by Incorporating Different Modes of PSSM into Chou's General PseAAC via Kullback-Leibler Divergence. Journal of Theoretical Biology, 454, 22-29. https://doi.org/10.1016/j.jtbi.2018.05.035

195. Mei, J., Fu, Y. and Zhao, J. (2018) Analysis and Prediction of Ion Channel Inhibitors by Using Feature Selection and Chou's General Pseudo Amino Acid Composition. Journal of Theoretical Biology, 456, 41-48. https://doi.org/10.1016/j.jtbi.2018.07.040

196. Mei, J. and Zhao, J. (2018) Analysis and Prediction of Presynaptic and Postsynaptic Neurotoxins by Chou's General Pseudo Amino Acid Composition and Motif Features. Journal of Theoretical Biology, 427, 147-153. https://doi.org/10.1016/j.jtbi.2018.03.034

197. Rahman, S.M., Shatabda, S., Saha, S., Kaykobad, M. and Sohel Rahman, M. (2018) DPP-PseAAC: A DNA-Binding Protein Prediction Model Using Chou's General PseAAC. Journal of Theoretical Biology, 452, 22-34. https://doi.org/10.1016/j.jtbi.2018.05.006

198. Sankari, E.S. and Manimegalai, D.D. (2018) Predicting Membrane Protein Types by Incorporating a Novel Feature Set into Chou's GENERAL PseAAC. Journal of Theoretical Biology, 455, 319-328. https://doi.org/10.1016/j.jtbi.2018.07.032

199. Srivastava, A., Kumar, R. and Kumar, M. (2018) BlaPred: Predicting and Classifying Beta-Lactamase Using a 3-Tier Prediction System via Chou's General PseAAC. Journal of Theoretical Biology, 457, 29-36. https://doi.org/10.1016/j.jtbi.2018.08.030

200. Zhang, S. and Duan, X. (2018) Prediction of Protein Subcellular Localization with Oversampling Approach and Chou's General PseAAC. Journal of Theoretical Biology, 437, 239-250. https://doi.org/10.1016/j.jtbi.2017.10.030

201. Adilina, S., Farid, D.M. and Shatabda, S. (2019) Effective DNA Binding Protein Prediction by Using Key Features via Chou's General PseAAC. Journal of Theoretical Biology, 460, 64-78. 
https://doi.org/10.1016/j.jtbi.2018.10.027

202. Behbahani, M., Nosrati, M., Moradi, M. and Mohabatkar, H. (2019) Using Chou's General Pseudo Amino Acid Composition to Classify Laccases from Bacterial and Fungal Sources via Chou's Five-Step Rule. Applied Biochemistry and Biotechnology, 190, 1035-1048. https://doi.org/10.1007/s12010-019-03141-8

203. Chen, G., Cao, M., Yu, J., Guo, X. and Shi, S. (2019) Prediction and Functional Analysis of Prokaryote Lysine Acetylation Site by Incorporating Six Types of Features into Chou's General PseAAC. Journal of Theoretical Biology, 461, 92-101. https://doi.org/10.1016/j.jtbi.2018.10.047

204. Shen, Y., Tang, J. and Guo, F. (2019) Identification of Protein Subcellular Localization via Integrating Evolutionary and Physicochemical Information into Chou's General PseAAC. Journal of Theoretical Biology, 462, 230-239. https://doi.org/10.1016/j.jtbi.2018.11.012

205. Wang, L., Zhang, R. and Mu, Y. (2019) Fu-SulfPred: Identification of Protein S-Sulfenylation Sites by Fusing Forests via Chou's General PseAAC. Journal of Theoretical Biology, 461, 51-58. https://doi.org/10.1016/j.jtbi.2018.10.046

206. Xiao, X., Cheng, X., Chen, G., Mao, Q. and Chou, K.C. (2019) pLoc_bal-mVirus: Predict Subcellular Localization of Multi-Label Virus Proteins by Chou's General PseAAC and IHTS Treatment to Balance Training Dataset. Journal of Medicinal Chemistry, 15, 496-509. https://doi.org/10.2174/1573406415666181217114710

207. Behbahani, M., Nosrati, M., Moradi, M. and Mohabatkar, H. (2020) Using Chou's General Pseudo Amino Acid Composition to Classify Laccases from Bacterial and Fungal Sources via Chou's Five-Step Rule. Applied Biochemistry and Biotechnology, 190, 1035-1048. https://doi.org/10.1007/s12010-019-03141-8

208. Chou, K.C. (2009) Pseudo Amino Acid Composition and Its Applications in Bioinformatics, Proteomics and System Biology. Current Proteomics, 6, 262-274. https://doi.org/10.2174/157016409789973707

209. Chen, W., Lei, T.Y., Jin, D.C., Lin, H. and Chou, K.C. (2014) PseKNC: A Flexible Web-Server for Generating Pseudo K-Tuple Nucleotide Composition. Analytical Biochemistry, 456, 53-60.

https://doi.org/10.1016/j.ab.2014.04.001

210. Chen, W., Lin, H. and Chou, K.C. (2015) Pseudo Nucleotide Composition or PseKNC: An Effective Formulation for Analyzing Genomic Sequences. Molecular BioSystems, 11, 2620-2634.

https://doi.org/10.1039/C5MB00155B

211. Chen, W., Feng, P.M., Lin, H. and Chou, K.C. (2014) iSS-PseDNC: Identifying Splicing Sites Using Pseudo Dinucleotide Composition. Biomed Research International (BMRI), 2014, Article ID: 623149.

https://doi.org/10.1155/2014/623149

212. Chen, W., Tang, H., Ye, J., Lin, H. and Chou, K.C. (2016) iRNA-PseU: Identifying RNA Pseudouridine Sites. Molecular Therapy-Nucleic Acids, 5, e332.

213. Liu, B., Fang, L., Long, R., Lan, X. and Chou, K.C. (2016) iEnhancer-2L: A Two-Layer Predictor for Identifying Enhancers and Their Strength by Pseudo k-Tuple Nucleotide Composition. Bioinformatics, 32, 362-369. https://doi.org/10.1093/bioinformatics/btv604

214. Liu, B., Long, R. and Chou, K.C. (2016) iDHS-EL: Identifying DNase I Hypersensitive Sites by Fusing Three Different Modes of Pseudo Nucleotide Composition into an Ensemble Learning Framework. Bioinformatics, 32, 2411-2418. https://doi.org/10.1093/bioinformatics/btw186

215. Feng, P., Ding, H., Yang, H., Chen, W., Lin, H. and Chou, K.C. (2017) iRNA-PseColl: Identifying the Occurrence Sites of Different RNA Modifications by Incorporating Collective Effects of Nucleotides into PseKNC. Molecular Therapy—Nucleic Acids, 7, 155-163. https://doi.org/10.1016/j.omtn.2017.03.006

216. Liu, B., Wang, S., Long, R. and Chou, K.C. (2017) iRSpot-EL: Identify Recombination Spots with an Ensemble Learning Approach. Bioinformatics, 33, 35-41. https://doi.org/10.1093/bioinformatics/btw539 
217. Liu, B., Yang, F. and Chou, K.C. (2017) 2L-piRNA: A Two-Layer Ensemble Classifier for Identifying Piwi-Interacting RNAs and Their Function. Molecular Therapy—Nucleic Acids, 7, 267-277. https://doi.org/10.1016/j.omtn.2017.04.008

218. Al Maruf, M.A. and Shatabda, S. (2018) iRSpot-SF: Prediction of Recombination Hotspots by Incorporating Sequence Based Features into Chou's Pseudo Components. Genomics. https://doi.org/10.1016/j.ygeno.2018.06.003

219. Sabooh, M.F., Iqbal, N., Khan, M., Khan, M. and Maqbool, H.F. (2018) Identifying 5-Methylcytosine Sites in RNA Sequence Using Composite Encoding Feature into Chou's PseKNC. Journal of Theoretical Biology, 452, 1-9. https://doi.org/10.1016/j.jtbi.2018.04.037

220. Zhang, L. and Kong, L. (2018) iRSpot-ADPM: Identify Recombination Spots by Incorporating the Associated Dinucleotide Product Model into Chou's Pseudo Components. Journal of Theoretical Biology, 441, 1-8. https://doi.org/10.1016/j.jtbi.2017.12.025

221. Zhang, S., Yang, K., Lei, Y. and Song, K. (2018) iRSpot-DTS: Predict Recombination Spots by Incorporating the Dinucleotide-Based Spare-Cross Covariance Information into Chou's Pseudo Components. Genomics, 11, 457-464.

222. Chou, K.C. (2019) Two Kinds of Metrics for Computational Biology. Genomics. https://www.sciencedirect.com/science/article/pii/S0888754319304604?via\%3Dihub

223. Chen, W., Feng, P.M., Lin, H. and Chou, K.C. (2013) iRSpot-PseDNC: Identify Recombination Spots with Pseudo Dinucleotide Composition. Nucleic Acids Research, 41, e68. https://doi.org/10.1093/nar/gks1450

224. Chou, K.C. (2001) Using Subsite Coupling to Predict Signal Peptides. Protein Engineering, 14, 75-79. https://doi.org/10.1093/protein/14.2.75

225. Jia, J., Liu, Z., Xiao, X., Liu, B. and Chou, K.C. (2016) Identification of Protein-Protein Binding Sites by Incorporating the Physicochemical Properties and Stationary Wavelet Transforms into Pseudo Amino Acid Composition (iPPBS-PseAAC). Journal of Biomolecular Structure and Dynamics (JBSD), 34, 1946-1961. https://doi.org/10.1080/07391102.2015.1095116

226. Xiao, X., Wang, P., Lin, W.Z., Jia, J.H. and Chou, K.C. (2013) iAMP-2L: A Two-Level Multi-Label Classifier for Identifying Antimicrobial Peptides and Their Functional Types. Analytical Biochemistry, 436, 168-177. https://doi.org/10.1016/j.ab.2013.01.019

227. Jia, J., Liu, Z., Xiao, X. and Chou, K.C. (2015) iPPI-Esml: An Ensemble Classifier for Identifying the Interactions of Proteins by Incorporating Their Physicochemical Properties and Wavelet Transforms into PseAAC. Journal of Theoretical Biology, 377, 47-56. https://doi.org/10.1016/j.jtbi.2015.04.011

228. Jia, J., Liu, Z., Xiao, X., Liu, B. and Chou, K.C. (2016) iSuc-PseOpt: Identifying Lysine Succinylation Sites in Proteins by Incorporating Sequence-Coupling Effects into Pseudo Components and Optimizing Imbalanced Training Dataset. Analytical Biochemistry, 497, 48-56. https://doi.org/10.1016/j.ab.2015.12.009

229. Jia, J., Liu, Z., Xiao, X., Liu, B. and Chou, K.C. (2016) pSuc-Lys: Predict Lysine Succinylation Sites in Proteins with PseAAC and Ensemble Random Forest Approach. Journal of Theoretical Biology, 394, 223-230. https://doi.org/10.1016/j.jtbi.2016.01.020

230. Jia, J., Liu, Z., Xiao, X., Liu, B. and Chou, K.C. (2016) iCar-PseCp: Identify Carbonylation Sites in Proteins by Monto Carlo Sampling and Incorporating Sequence Coupled Effects into General PseAAC. Oncotarget, 7, 34558-34570. https://doi.org/10.18632/oncotarget.9148

231. Jia, J., Liu, Z., Xiao, X., Liu, B. and Chou, K.C. (2016) iPPBS-Opt: A Sequence-Based Ensemble Classifier for Identifying Protein-Protein Binding Sites by Optimizing Imbalanced Training Datasets. Molecules, 21, E95. https://doi.org/10.3390/molecules21010095 
232. Jia, J., Zhang, L., Liu, Z., Xiao, X. and Chou, K.C. (2016) pSumo-CD: Predicting Sumoylation Sites in Proteins with Covariance Discriminant Algorithm by Incorporating Sequence-Coupled Effects into General PseAAC. Bioinformatics, 32, 3133-3141. https://doi.org/10.1093/bioinformatics/btw387

233. Liu, Z., Xiao, X., Yu, D.J., Jia, J., Qiu, W.R. and Chou, K.C. (2016) pRNAm-PC: Predicting N-Methyladenosine Sites in RNA Sequences via Physical-Chemical Properties. Analytical Biochemistry, 497, 60-67. https://doi.org/10.1016/j.ab.2015.12.017

234. Xiao, X., Ye, H.X., Liu, Z., Jia, J.H. and Chou, K.C. (2016) iROS-gPseKNC: Predicting Replication Origin Sites in DNA by Incorporating Dinucleotide Position-Specific Propensity into General Pseudo Nucleotide Composition. Oncotarget, 7, 34180-34189. https://doi.org/10.18632/oncotarget.9057

235. Qiu, W.R., Sun, B.Q., Xiao, X., Xu, Z.C., Jia, J.H. and Chou, K.C. (2018) iKcr-PseEns: Identify Lysine Crotonylation Sites in Histone Proteins with Pseudo Components and Ensemble Classifier. Genomics, 110, 239-246. https://doi.org/10.1016/j.ygeno.2017.10.008

236. Jia, J., Li, X., Qiu, W., Xiao, X. and Chou, K.C. (2019) iPPI-PseAAC(CGR): Identify Protein-Protein Interactions by Incorporating Chaos Game Representation into PseAAC. Journal of Theoretical Biology, 460, 195-203. https://doi.org/10.1016/j.jtbi.2018.10.021

237. Xu, Y., Ding, J., Wu, L.Y. and Chou, K.C. (2013) iSNO-PseAAC: Predict Cysteine S-Nitrosylation Sites in Proteins by Incorporating Position Specific Amino Acid Propensity into Pseudo Amino Acid Composition PLoS ONE, 8, e55844. https://doi.org/10.1371/journal.pone.0055844

238. Xu, Y., Shao, X.J., Wu, L.Y., Deng, N.Y. and Chou, K.C. (2013) iSNO-AAPair: Incorporating Amino Acid Pairwise Coupling into PseAAC for Predicting Cysteine S-Nitrosylation Sites in Proteins. Peer), 1, e171. https://doi.org/10.7717/peerj.171

239. Xu, Y., Wen, X., Shao, X.J., Deng, N.Y. and Chou, K.C. (2014) iHyd-PseAAC: Predicting Hydroxyproline and Hydroxylysine in Proteins by Incorporating Dipeptide Position-Specific Propensity into Pseudo Amino Acid Composition. International Journal of Molecular Sciences, 15, 7594-7610. https://doi.org/10.3390/ijms15057594

240. Xu, Y., Wen, X., Wen, L.S., Wu, L.Y., Deng, N.Y. and Chou, K.C. (2014) iNitro-Tyr: Prediction of Nitrotyrosine Sites in Proteins with General Pseudo Amino Acid Composition. PLoS ONE, 9, e105018. https://doi.org/10.1371/journal.pone.0105018

241. Xu, Y. and Chou, K.C. (2016) Recent Progress in Predicting Posttranslational Modification Sites in Proteins. Current Topics in Medicinal Chemistry, 16, 591-603. https://doi.org/10.2174/1568026615666150819110421

242. Liu, L.M., Xu, Y. and Chou, K.C. (2017) iPGK-PseAAC: Identify Lysine Phosphoglycerylation Sites in Proteins by Incorporating Four Different Tiers of Amino Acid Pairwise Coupling Information into the General PseAAC. Journal of Medicinal Chemistry, 13, 552-559. https://doi.org/10.2174/1573406413666170515120507

243. Xu, Y., Li, C. and Chou, K.C. (2017) iPreny-PseAAC: Identify C-Terminal Cysteine Prenylation Sites in Proteins by Incorporating Two Tiers of Sequence Couplings into PseAAC. Journal of Medicinal Chemistry, 13, 544-551. https://doi.org/10.2174/1573406413666170419150052

244. Liu, B., Zhang, D., Xu, R., Xu, J., Wang, X., Chen, Q., Dong, Q. and Chou, K.C. (2014) Combining Evolutionary Information Extracted from Frequency Profiles with Sequence-Based Kernels for Protein Remote Homology Detection. Bioinformatics, 30, 472-479. https://doi.org/10.1093/bioinformatics/btt709

245. Chen, J., Long, R., Wang, X.L., Liu, B. and Chou, K.C. (2016) dRHP-PseRA: Detecting Remote Homology Proteins Using Profile-Based Pseudo Protein Sequence and Rank Aggregation. Scientific Reports, 6, Article No. 32333. https://doi.org/10.1038/srep32333

246. Xu, R., Zhou, J., Liu, B., He, Y.A., Zou, Q., Wang, X. and Chou, K.C. (2015) Identification of DNA-Binding Proteins by Incorporating Evolutionary Information into Pseudo Amino Acid Composition via the Top-N-Gram 
Approach. Journal of Biomolecular Structure \& Dynamics (JBSD), 33, 1720-1730.

https://doi.org/10.1080/07391102.2014.968624

247. Liu, B., Fang, L., Wang, S., Wang, X., Li, H. and Chou, K.C. (2015) Identification of microRNA Precursor with the Degenerate K-tuple or Kmer Strategy. Journal of Theoretical Biology, 385, 153-159. https://doi.org/10.1016/j.jtbi.2015.08.025

248. Liu, B., Fang, L., Liu, F., Wang, X., Chen, J. and Chou, K.C. (2015) Identification of Real microRNA Precursors with a Pseudo Structure Status Composition Approach. PLoS ONE, 10, e0121501. https://doi.org/10.1371/journal.pone.0121501

249. Liu, B., Xu, J., Lan, X., Xu, R., Zhou, J., Wang, X. and Chou, K.C. (2014) iDNA-Prot|dis: Identifying DNA-Binding Proteins by Incorporating Amino Acid Distance-Pairs and Reduced Alphabet Profile into the General Pseudo Amino Acid Composition. PLoS ONE, 9, e106691. https://doi.org/10.1371/journal.pone.0106691

250. Liu, B., Li, K., Huang, D.S. and Chou, K.C. (2018) iEnhancer-EL: Identifying Enhancers and Their Strength with Ensemble Learning Approach. Bioinformatics, 34, 3835-3842. https://doi.org/10.1093/bioinformatics/bty 458

251. Liu, B., Yang, F., Huang, D.S. and Chou, K.C. (2018) iPromoter-2L: A Two-Layer Predictor for Identifying Promoters and Their Types by Multi-Window-Based PseKNC. Bioinformatics, 34, 33-40. https://doi.org/10.1093/bioinformatics/btx579

252. Liu, B., Weng, F., Huang, D.S. and Chou, K.C. (2018) iRO-3wPseKNC: Identify DNA Replication Origins by Three-Window-Based PseKNC. Bioinformatics, 34, 3086-3093. https://doi.org/10.1093/bioinformatics/bty312

253. Liu, B., Wu, H., Zhang, D., Wang, X. and Chou, K.C. (2017) Pse-Analysis: A Python Package for DNA/RNA and Protein/Peptide Sequence Analysis Based on Pseudo Components and Kernel Methods. Oncotarget, 8, 13338-13343. https://doi.org/10.18632/oncotarget.14524

254. Liu, B., Wu, H. and Chou, K.C. (2017) Pse-in-One 2.0: An Improved Package of Web Servers for Generating Various Modes of Pseudo Components of DNA, RNA, and Protein Sequences. Natural Science, 9, 67-91. https://doi.org/10.4236/ns.2017.94007

255. Liu, B., Liu, F., Wang, X., Chen, J., Fang, L. and Chou, K.C. (2015) Pse-in-One: A Web Server for Generating Various Modes of Pseudo Components of DNA, RNA, and Protein Sequences. Nucleic Acids Research, 43, W65-W71. https://doi.org/10.1093/nar/gkv458

256. Liu, B., Liu, F., Fang, L., Wang, X. and Chou, K.C. (2015) repDNA: A Python Package to Generate Various Modes of Feature Vectors for DNA Sequences by Incorporating User-Defined Physicochemical Properties and Sequence-Order Effects. Bioinformatics, 31, 1307-1309. https://doi.org/10.1093/bioinformatics/btu820

257. Liu, B., Liu, F., Fang, L., Wang, X. and Chou, K.C. (2016) repRNA: A Web Server for Generating Various Feature Vectors of RNA Sequences. Molecular Genetics and Genomics, 291, 473-481. https://doi.org/10.1007/s00438-015-1078-7

258. Chen, W., Feng, P., Ding, H., Lin, H. and Chou, K.C. (2015) Benchmark Data for Identifying N6-Methyladenosine Sites in the Saccharomyces cerevisiae Genome. Data in Brief, 5, 376-378. https://doi.org/10.1016/j.dib.2015.09.008

259. Chen, W., Ding, H., Feng, P., Lin, H. and Chou, K.C. (2016) iACP: A Sequence-Based Tool for Identifying Anticancer Peptides. Oncotarget, 7, 16895-16909. https://doi.org/10.18632/oncotarget.7815

260. Feng, P., Yang, H., Ding, H., Lin, H., Chen, W. and Chou, K.C. (2019) iDNA6mA-PseKNC: Identifying DNA N(6)-methyladenosine Sites by Incorporating Nucleotide Physicochemical Properties into PseKNC. Genomics, 111, 96-102. https://doi.org/10.1016/j.ygeno.2018.01.005

261. Feng, P.M., Chen, W., Lin, H. and Chou, K.C. (2013) iHSP-PseRAAAC: Identifying the Heat Shock Protein 
Families Using Pseudo Reduced Amino Acid Alphabet Composition. Analytical Biochemistry, 442, 118-125. https://doi.org/10.1016/j.ab.2013.05.024

262. Su, Z.D., Huang, Y., Zhang, Z.Y., Zhao, Y.W., Wang, D., Chen, W., Chou, K.C. and Lin, H. (2018) iLoc-lncRNA: Predict the Subcellular Location of lncRNAs by Incorporating Octamer Composition into General PseKNC. Bioinformatics, 34, 4196-4204.

263. Chen, W., Lin, H., Feng, P.M., Ding, C., Zuo, Y.C. and Chou, K.C. (2012) iNuc-PhysChem: A Sequence-Based Predictor for Identifying Nucleosomes via Physicochemical Properties. PLoS ONE, 7, e47843. https://doi.org/10.1371/journal.pone.0047843

264. Guo, S.H., Deng, E.Z., Xu, L.Q., Ding, H., Lin, H., Chen, W. and Chou, K.C. (2014) iNuc-PseKNC: A Sequence-Based Predictor for Predicting Nucleosome Positioning in Genomes with Pseudo k-tuple Nucleotide Composition. Bioinformatics, 30, 1522-1529. https://doi.org/10.1093/bioinformatics/btu083

265. Zhang, C.J., Tang, H., Li, W.C., Lin, H., Chen, W. and Chou, K.C. (2016) iOri-Human: Identify Human Origin of Replication by Incorporating Dinucleotide Physicochemical Properties into Pseudo Nucleotide Composition. Oncotarget, 7, 69783-69793. https://doi.org/10.18632/oncotarget.11975

266. Lin, H., Deng, E.Z., Ding, H., Chen, W. and Chou, K.C. (2014) iPro54-PseKNC: A Sequence-Based Predictor for Identifying Sigma-54 Promoters in Prokaryote with Pseudo k-tuple Nucleotide Composition. Nucleic Acids Research, 42, 12961-12972. https://doi.org/10.1093/nar/gku1019

267. Chen, W., Feng, P., Yang, H., Ding, H., Lin, H. and Chou, K.C. (2018) iRNA-3typeA: Identifying 3-Types of Modification at RNA's Adenosine Sites. Molecular Therapy. Nucleic Acid, 11, 468-474. https://doi.org/10.1016/j.omtn.2018.03.012

268. Chen, W., Feng, P., Yang, H., Ding, H., Lin, H. and Chou, K.C. (2017) iRNA-AI: Identifying the Adenosine to Inosine Editing Sites in RNA Sequences. Oncotarget, 8, 4208-4217. https://doi.org/10.18632/oncotarget.13758

269. Chen, W., Feng, P., Ding, H., Lin, H. and Chou, K.C. (2015) iRNA-Methyl: Identifying N6-methyladenosine Sites Using Pseudo Nucleotide Composition. Analytical Biochemistry, 490, 26-33. https://doi.org/10.1016/j.ab.2015.08.021

270. Chen, W., Ding, H., Zhou, X., Lin, H. and Chou, K.C. (2018) iRNA(m6A)-PseDNC: Identifying N6-methyladenosine Sites Using Pseudo Dinucleotide Composition. Analytical Biochemistry, 561-562, 59-65. https://doi.org/10.1016/j.ab.2018.09.002

271. Yang, H., Qiu, W.R., Liu, G., Guo, F.B., Chen, W., Chou, K.C. and Lin, H. (2018) iRSpot-Pse6NC: Identifying Recombination Spots in Saccharomyces cerevisiae by Incorporating Hexamer Composition into General PseKNC. International Journal of Biological Sciences, 14, 883-891. https://doi.org/10.7150/ijbs.24616

272. Chen, W., Feng, P.M., Deng, E.Z., Lin, H. and Chou, K.C. (2014) iTIS-PseTNC: A Sequence-Based Predictor for Identifying Translation Initiation Site in Human Genes Using Pseudo Trinucleotide Composition. Analytical Biochemistry, 462, 76-83. https://doi.org/10.1016/j.ab.2014.06.022

273. Chen, W., Zhang, X., Brooker, J., Lin, H., Zhang, L. and Chou, K.C. (2015) PseKNC-General: A Cross-Platform Package for Generating Various Modes of Pseudo Nucleotide Compositions. Bioinformatics, 31, 119-120. https://doi.org/10.1093/bioinformatics/btu602

274. Chen, W., Feng, P., Ding, H., Lin, H. and Chou, K.C. (2016) Using Deformation Energy to Analyze Nucleosome Positioning in Genomes. Genomics, 107, 69-75. https://doi.org/10.1016/j.ygeno.2015.12.005

275. Chou, K.C. (2020) The Development of Gordon Life Science Institute: Its Driving Force and Accomplishments. Natural Science, 12, 202-217. https://doi.org/10.4236/ns.2020.124018

276. Chou, K.C. (2020) The Most Important Ethical Concerns in Science. Natural Science, 12, 35-36. https://doi.org/10.4236/ns.2020.122005 
277. Chou, K.C. (2020) Other Mountain Stones Can Attack Jade: The 5-Steps Rule. Natural Science, 12, 59-64. https://doi.org/10.4236/ns.2020.123011

278. Chou, K.C. (2020) The Problem of Elsevier Series Journals Online Submission by Using Artificial Intelligence. Natural Science, 12, 37-38. https://doi.org/10.4236/ns.2020.122006

279. Chou, K.C. (2020) Proposing 5-Steps Rule Is a Notable Milestone for Studying Molecular Biology. Natural Science, 12, 74-79. https://doi.org/10.4236/ns.2020.123011

280. Chou, K.C. (2020) Using Similarity Software to Evaluate Scientific Paper Quality Is a Big Mistake. Natural Science, 12, 42-58. https://doi.org/10.4236/ns.2020.123008

281. Tsoumakas, G., Katakis, I. and Vlahavas, I. (2010) Random k-Labelsets for Multilabel Classification IEEE Transactions on Knowledge and Data Engineering, 23, 1079-1089. https://doi.org/10.1109/TKDE.2010.164

282. Tsoumakas, G. and Katakis, L. (2007) Multi-Label Classification: An Overview International Journal of Data Warehousing and Mining, 3, 13. https://doi.org/10.4018/jdwm.2007070101

283. Abdul Rahman, M.B., Karjiban, R.A., Salleh, A.B., Jacobs, D., Basri, M., Thean Chor, A.L., Abdul Wahab, H. and Rahman, R.N. (2009) Deciphering the Flexibility and Dynamics of Geobacillus Zalihae Strain T1 Lipase at High Temperatures by Molecular Dynamics Simulation. Protein \& Peptide Letters, 16, 1360-1370. https://doi.org/10.2174/092986609789353763

284. Breiman, L. (2001) Random Forests. Machine Learning, 45, 5-32. https://doi.org/10.1023/A:1010933404324

285. Zhang, T.L. and Ding, Y.S. (2007) Using Pseudo Amino Acid Composition and Binary-Tree Support Vector Machines to Predict Protein Structural Classes. Amino Acids, 33, 623-629. https://doi.org/10.1007/s00726-007-0496-1

286. Chou, K.C. and Shen, H.B. (2009) Recent Advances in Developing Web-Servers for Predicting Protein Attributes. Natural Science, 1, 63-92. https://doi.org/10.4236/ns.2009.12011

287. Chou, K.C. (2017) An Unprecedented Revolution in Medicinal Chemistry Driven by the Progress of Biological Science. Current Topics in Medicinal Chemistry, 17, 2337-2358. https://doi.org/10.2174/1568026617666170414145508 